\title{
Nonlinear Dynamics in Nasdaq Dealer Quotes
}

Citation for published version (APA):

Frijns, B. P. M., \& Schotman, P. C. (2006). Nonlinear Dynamics in Nasdaq Dealer Quotes. Computational Statistics \& Data Analysis, 51(4), 2246-2266. https://doi.org/10.1016/j.csda.2006.09.011

Document status and date:

Published: 01/01/2006

DOI:

10.1016/j.csda.2006.09.011

Document Version:

Publisher's PDF, also known as Version of record

Document license:

Taverne

Please check the document version of this publication:

- A submitted manuscript is the version of the article upon submission and before peer-review. There can be important differences between the submitted version and the official published version of record.

People interested in the research are advised to contact the author for the final version of the publication, or visit the DOI to the publisher's website.

- The final author version and the galley proof are versions of the publication after peer review.

- The final published version features the final layout of the paper including the volume, issue and page numbers.

Link to publication

\footnotetext{
General rights rights.

- You may freely distribute the URL identifying the publication in the public portal. please follow below link for the End User Agreement:

www.umlib.nl/taverne-license

Take down policy

If you believe that this document breaches copyright please contact us at:

repository@maastrichtuniversity.nl

providing details and we will investigate your claim.
}

Copyright and moral rights for the publications made accessible in the public portal are retained by the authors and/or other copyright owners and it is a condition of accessing publications that users recognise and abide by the legal requirements associated with these

- Users may download and print one copy of any publication from the public portal for the purpose of private study or research.

- You may not further distribute the material or use it for any profit-making activity or commercial gain

If the publication is distributed under the terms of Article $25 \mathrm{fa}$ of the Dutch Copyright Act, indicated by the "Taverne" license above, 


\title{
Nonlinear dynamics in Nasdaq dealer quotes
}

\author{
Bart Frijns $^{\mathrm{a}, *}$, Peter C. Schotman ${ }^{\mathrm{b}}$ \\ ${ }^{a}$ Nijmegen School of Management, Radboud University Nijmegen, P.O. Box 9108, 6500 HK Nijmegen, The Netherlands \\ ${ }^{\mathrm{b}}$ LIFE, Maastricht University, P.O. Box 616, 6200 MD Maastricht, The Netherlands, and CEPR
}

Available online 9 October 2006

\begin{abstract}
A nonlinear dynamic model for the quotes issued by Nasdaq dealers is considered. The model focusses on the top two electronic communication networks (ECNs), Island and Instinet, and the three most active market makers for a sample of twenty stocks. The model extends the standard linear vector error correction model for price discovery in three different ways. First, quote adjustments are set relative to the inside quote, i.e. the best bid and ask in the market. Second, dealers react to the inside spread. Third, adjustments differ according to which dealer is currently at the inside. Adjustments are different if an ECN is currently at the inside compared to an individual dealer. This difference is attributed to the asymmetric information among dealers. Price discovery dynamics are studied using generalized impulse response functions.
\end{abstract}

(C) 2006 Elsevier B.V. All rights reserved.

Keywords: High frequency data; Dealer markets; Error correction models; Nonlinear impulse-response functions

\section{Introduction}

Price discovery is an important aspect of the functioning of financial markets. It measures which participants contribute most effectively to incorporating fundamental news about the value of a security. Measures of price discovery are typically derived from a dynamic model of prices (or quotes) of the same asset at different markets or by different participants on a market.

The best known price discovery measure has been developed by Hasbrouck (1995). It is based on a reduced form vector error correction model of prices. The only drivers of the price dynamics in this model are past prices. Contributions to price discovery are derived from the long-run impulse responses of shocks from different market participants. Next to the original application to equity prices at different regional exchanges, the Hasbrouck (1995) methodology has been applied in various other settings. A few examples are Eun and Sabherwal (2003) who study internationally cross-listed firms, Peiers (1997) who looks at banks dealing in the foreign exchange market, and Huang (2002) who investigates the role of electronic communication networks (ECNs) on the Nasdaq.

Apart from past prices, there are various other factors that influence price dynamics. Examples are traded volume, trade direction and stock price volatility. For stock markets these external factors have been investigated by Hasbrouck (1991, 1999), Harris et al. (1995) and Engle and Patton (2004) among others.

\footnotetext{
* Corresponding author. Tel.: +31 243611599 ; fax: +31 243612379 .

E-mail addresses: b.frijns@fm.ru.nl (B. Frijns), p.schotman@ finance.unimaas.nl (P.C. Schotman).
} 
This paper emphasizes the role of an additional variable in the dynamics. Like Huang (2002), we consider the relation between ECNs and individual dealers on Nasdaq, but we add more detail to the dynamic model. An important piece of information to dealers are the inside quotes, i.e. the best bid and offer quotes. We include dummy variables that indicate who is at the inside at any given time. These dummies should reveal whether being at the inside is informative to other dealers. Due to their internal crossing, the inside quotes most often come from an ECN. When one of the individual dealers moves to the inside, this could signal important information and lead to different reactions by other dealers. In our model this brings an important nonlinearity into the vector error correction model. Other nonlinearities include the adjustment itself. Instead of an error correction towards the midpoint of quotes, we empirically show that the adjustment is towards the inside quotes.

As we focus on the informational role of the inside quotes, our model for quote dynamics is related to models of information asymmetries across dealers. For the Nasdaq, informational asymmetries across different dealers have been addressed by Huang (2002). For several categories of dealers, he evaluates the informational asymmetry between dealers in terms of price discovery by computing Hasbrouck (1995) information shares of ECNs versus non-ECNs. However, Huang (2002) focuses on the (non)presence of asymmetric information and not on the consequences of this asymmetry on the quote setting of dealers. We extend this work by looking at the consequences of this asymmetry on the dynamics of dealer quotes.

The nonlinear model is motivated by the developments that have taken place at the Nasdaq. Since the studies of Christie and Schultz (1994) and Christie et al. (1994) there has been a fierce discussion about competition at Nasdaq. In 1997, the order handling rule (OHR), stating that all trades have to be executed at the national best bid or offer, reduced the tick size and further liberalized the operations of ECNs. This rule brought a great change to the competitive nature of trade at Nasdaq. Nowadays over $60 \%$ of quotes are issued by ECNs, which are also considered to be most efficient in terms of quote setting (see e.g. Huang, 2002). Efficient ECN quotes would prohibit potential collusion at Nasdaq, since ECNs would only suffer from keeping prices above the level of marginal costs. Because being at the inside attracts order flow, dealers compete to be at the inside and this competition should have increased with the liberalization of ECNs. However, dealers will only improve the inside quote by the smallest possible amount. Any further improvement would only reduce her profits. For these reasons (increased competition and marginal improvement beyond the inside) we propose an error correction towards the inside quote, instead of the midpoint (see Hasbrouck, 1991). This effect should be stronger after the introduction of the OHR as competition for order flow increased.

Since ECNs are at the inside quotes most of the time, dealer quotes will become more indicative. Dealer quotes would then be a means of disseminating information. When a dealer, who is normally not at the inside, sets the inside quote, this can signal information about either her inventory position or information she might possess. We therefore argue that being at the inside reveals information and other dealers might respond to this. This motivates the inclusion of an indicator function for dealers being at the inside.

The model we propose is designed to model the dynamic interaction in dealer quotes. It can be seen as part of a more general VAR that also describes the trade process (see Hasbrouck, 1991). However, as we are interested in describing the interaction of dealer quotes, we only focus on the quote setting process and therefore exclude other external factors that influence the quote setting process (see Engle and Patton, 2004).

With a nonlinear model the price discovery measures of Hasbrouck (1995) can not be applied unconditionally. In a nonlinear model the reaction to a shock depends on the state of the system (i.e. who is currently setting the inside quotes) and on the size and direction of the shock, i.e. moving towards or away from the inside. We use the generalized impulse response functions of Koop et al. (1996) to analyze the impact of quote changes on other dealer quotes. In our empirical analysis we consider the top two ECNs, Island and Instinet, and the top three market makers, in terms of quoting frequency, of 20 actively traded stocks at Nasdaq.

We find that the nonlinear specification significantly improves the linear specification of Hasbrouck (1991), where the largest improvement is caused by the inclusion of the inside dummies. Dealers correct strongly towards the inside quote, but, except for Island, tend to move away from it when they have reached it. Overall, when Island sets the inside quote, dealers adjust their quotes to the inside as well. This effect is not present when any of the other dealers is at the inside. We further find that all dealers have the tendency to keep spreads small, but that this effect is strongest for ECNs. Price discovery is addressed in terms of impulse response functions. These functions not only allow us to determine the impact that a dealer's quoting behavior has on the quotes of other dealers, but also allow us to evaluate the speed at which this adjustment takes place. We compute impulse response functions for both the linear and the 
nonlinear model. We find that the impulse responses for the nonlinear model lead to important differences compared to the impulse responses of the linear model.

The remainder of this paper is structured as follows. In the next section we propose a nonlinear adjustment model for dealer quotes, which is a generalization of the linear model. We further show how dealer efficiency can be measured with nonlinear impulse-responses. In Section 3 we address the data used in this study. Section 4 presents the empirical results of our models and discusses the results of the impulse responses. Finally, Section 5 concludes.

\section{The model}

In this section we specify a nonlinear model for the dynamic interaction between dealer quotes. The model can be seen as a generalization of the linear vector error correction model proposed by Hasbrouck (1991). We further propose an alternative decomposition for quotes to the decomposition of Hasbrouck (1995), for which we can analyze price discovery in terms of impulse response functions.

For an actively traded stock at Nasdaq we consider bid and ask quotes from the $N$ most active dealers in terms of quoting frequency. For each dealer $i$, let $b_{i t} \equiv \log \left(\operatorname{Bid}_{i t}\right)$, where $\operatorname{Bid}_{i t}$ is the bid quote of dealer $i$ at time $t$. Likewise define $a_{i t} \equiv \log \left(\mathrm{Ask}_{i t}\right)$. These quotes are stacked in the vectors $b_{t} \equiv\left(b_{1 t}, \ldots, b_{N t}\right)^{\prime}$ and $a_{t} \equiv\left(a_{1 t}, \ldots, a_{N t}\right)^{\prime}$. We further define the inside quotes $i q_{t}^{b}$ as the highest bid over all dealers and $i q_{t}^{a}$ as the lowest ask over all dealers. In the data these inside quotes are determined over all dealer quotes and not only the $N$ most active. Finally, we define the $2 N$-vector of inside dummies $I_{t}=\left(I_{t}^{b^{\prime}} I_{t}^{a \prime}\right)^{\prime}$. An element $I_{i t}^{a}$ is equal to one if dealer $i$ is at the inside ask $\left(a_{i t}=i q_{t}^{a}\right)$. Analogously, $I_{i t}^{b}=1$, if $b_{i t}=i q_{t}^{b}$. These inside dummies and the inside quotes are both nonlinear functions of the bid and ask quotes. We propose the following nonlinear vector error correction model for the dynamic interaction in dealer quotes,

$$
\begin{aligned}
\left(\begin{array}{c}
\Delta b_{t} \\
\Delta a_{t}
\end{array}\right)= & C_{t}(\cdot)+\Gamma I_{t-1}+\Phi\left(\begin{array}{c}
\Delta b_{t-1} \\
\Delta a_{t-1}
\end{array}\right)+\Psi\left(\begin{array}{c}
b_{t-1}-\imath i q_{t-1}^{b} \\
a_{t-1}-\imath i q_{t-1}^{a}
\end{array}\right) \\
& +\theta\left(i q_{t-1}^{a}-i q_{t-1}^{b}\right)+\left(\begin{array}{c}
\eta_{t}^{b} \\
\eta_{t}^{a}
\end{array}\right),
\end{aligned}
$$

where the matrices $\Gamma, \Phi$ and $\Psi$ are all of dimension $(2 N \times 2 N), \theta$ is a $(2 N \times 1)$ vector and $l$ is a $(N \times 1)$ unit vector. $C_{t}(\cdot)$ is a deterministic function of constants, $C_{t}(\cdot)=\alpha_{0}+\alpha_{1} D_{t}^{\mathrm{O}}+\alpha_{2} D_{t}^{\mathrm{S}}$, where $\alpha_{0}, \alpha_{1}$, and $\alpha_{2}$ are $(2 N \times 1)$ parameter vectors, $D_{t}^{\mathrm{O}}$ is a dummy variable equal to 1 if the observation is for an overnight period and zero otherwise, and $D_{t}^{\mathrm{S}}$ is a dummy variable used if a stock split occurred. It equals 1 before the split and 0 after. The innovation terms $\eta_{t}^{b}$ and $\eta_{t}^{a}$ are assumed to be independently distributed, and we will later introduce a specific structure on their conditional covariances.

The model contains two important nonlinearities. First, inside dummies are included because being at the inside might reveal information. For example, when dealer $i$, who is seldom at the inside, reaches the inside, information might be revealed to other dealers. The opposite also holds: a dealer who often quotes the inside, might reveal information when not quoting the inside (see e.g. Stoll, 1989). The regime-dependent expected quote adjustments are an important source of nonlinearity.

Second, dealers adjust their quotes relative to the deviation from the inside quotes, instead of the midquote. To relate (1) to the linear error correction model, partition $\Psi$ and $\theta$ as

$$
\Psi=\left(\begin{array}{ll}
\Psi^{b b} & \Psi^{b a} \\
\Psi^{a b} & \Psi^{a a}
\end{array}\right), \quad \theta=\left(\begin{array}{c}
\theta^{b} \\
\theta^{a}
\end{array}\right) .
$$

Eq. (1) reduces to a linear VECM if $\Gamma=0$ and the inside quotes can be eliminated,

$$
\left(\begin{array}{cc}
\Psi^{b b} & \Psi^{b a} \\
\Psi^{a b} & \Psi^{a a}
\end{array}\right)\left(\begin{array}{cc}
-l & \mathbf{0} \\
\mathbf{0} & -l
\end{array}\right)\left(\begin{array}{l}
i q_{t-1}^{b} \\
i q_{t-1}^{a}
\end{array}\right)+\left(\begin{array}{c}
\theta^{b} \\
\theta^{a}
\end{array}\right)\left(\begin{array}{ll}
-1 & 1
\end{array}\right)\left(\begin{array}{c}
i q_{t-1}^{b} \\
i q_{t-1}^{a}
\end{array}\right)=\left(\begin{array}{c}
\mathbf{0} \\
\mathbf{0}
\end{array}\right)
$$

where $\mathbf{0}$ is an $N$-vector of zeros. This results in the following $4 N$ parameter restrictions

$$
\begin{array}{ll}
\left(\Psi^{b b}+\Psi^{b a}\right) l=\mathbf{0}, & \theta^{b}=-\Psi^{b b} l, \\
\left(\Psi^{a b}+\Psi^{a a}\right) l=\mathbf{0}, & \theta^{a}=\Psi^{a a} l .
\end{array}
$$


In the restricted model the rows of $\Psi$ add up to zero, which imposes linear cointegration upon the model. With these restrictions the inside quotes disappear from the model and the model takes the basic form as in Hasbrouck (1991) and Wang (2001). A Wald test, considering a $\chi^{2}$ distribution with $4 N$ degrees of freedom, can be used to test the linear model against the nonlinear one. Similarly, we test the hypothesis $\Gamma=0$ using a Wald test that is asymptotically $\chi^{2}\left(4 N^{2}\right)$.

The last part of the specification concerns the possible regime-dependence of the error covariance matrix. As being at the inside may alter the behavior of a dealer (quoting with specific information can be different from quoting without specific information) we expect the innovation term $\eta_{t}=\left(\eta_{t}^{b^{\prime}} \eta_{t}^{a^{\prime}}\right)^{\prime}$ to differ depending on whether a dealer is at the inside or not. Define $\Omega_{t}=\mathrm{E}\left[\eta_{t} \eta_{t}^{\prime}\right]$ as the conditional covariance matrix of quote innovations at time $t$ given the position of the dealers relative to the inside quotes. The covariance matrix has the natural partitioning in blocks $\Omega_{t}^{a a}, \Omega_{t}^{a b}$ and $\Omega_{t}^{b b}$. For $h=a a, a b, b b$, we specify

$$
\begin{aligned}
& \Omega_{i i, t+1}^{h}=\omega_{0 i}^{h}+\omega_{1 i}^{h} I_{i t}^{b}+\omega_{2 i}^{h} I_{i t}^{a}, \\
& \Omega_{i j, t+1}^{h}=\lambda_{0 i j}^{h}+\lambda_{1 i j}^{h} I_{i t}^{b}+\lambda_{2 i j}^{h} I_{i t}^{a}+\lambda_{3 i j}^{h} I_{j t}^{b}+\lambda_{4 i j}^{h} I_{j t}^{a},
\end{aligned}
$$

where $\Omega_{i j, t}^{h}$ is the covariance between a particular quote of dealer $i$ and dealer $j$. We test the null hypothesis that the parameters $\omega_{1 i}, \omega_{2 i}$ and $\lambda_{1 j}, \lambda_{2 j}, \lambda_{3 j}, \lambda_{4 j}$ are jointly equal to zero. To test for such regime-dependent heteroskedasticity we perform a Breusch-Pagan test (Breusch and Pagan, 1979).

To discuss dealer efficiency and price discovery we opt for an alternative approach than the approach proposed by Hasbrouck (1995) and applied by Huang (2002). Hasbrouck (1995) considers the amount of variance each dealer contributes to the total variance of the price process. However, a unique decomposition does not exist when quote innovations are contemporaneously correlated. More important, in a nonlinear system the decomposition is conditional on the type of shock and state of the system. We therefore opt for an alternative approach by computing impulse response functions. These functions are computed for both the nonlinear model in (1) and the linear specification where the dummy variables are excluded and the restrictions in (4) are imposed.

In impulse response functions an initial shock is applied to the model after which the outcome of the shock is evaluated. As the main model that we estimate is nonlinear, we cannot compute standard linear impulse response functions. For nonlinear models, the impulse response functions depend on the history of the model (i.e. the situation the market is in) and the size of the shock applied. For linear models, impulse responses do not depend on this and they can be calculated in the normal way. To determine these nonlinear impulse responses we apply the methodology as proposed by Koop et al. (1996). However, before discussing this methodology we first define what an appropriate shock size is.

We are interested in determining what impact private information of a particular dealer has on the quotes of other dealers and the level of prices. To find this private shock size, we decompose the quote innovations $\eta_{t}^{b}$ and $\eta_{t}^{a}$ into two components. The first component refers to a market-wide shock common to all dealers and can be seen as the public information shared by these dealers. The second component is dealer specific and can be seen as the private information of a dealer. As the private information is known to only this dealer, this can affect both bid and ask quote and we therefore allow for correlation between the bid and the ask of this dealer.

We propose the following decomposition of the innovation terms $\eta_{t}^{b}$ and $\eta_{t}^{a}$,

$$
\begin{aligned}
& \eta_{t}^{b}=\varepsilon_{t} \imath+\xi_{t}^{b} \\
& \eta_{t}^{a}=\varepsilon_{t} \imath+\xi_{t}^{a}
\end{aligned}
$$

where $\varepsilon_{t}$ is the market-wide or fundamental noise and $\xi_{t}^{b}$ and $\xi_{t}^{a}$ represent the dealers' idiosyncratic noise components. Our main interest is in the dealer specific shocks as they indicate how other dealers react to private information. We make the following assumptions regarding the components in (7),

$$
\begin{aligned}
& \mathrm{E}\left[\varepsilon_{t}^{2}\right]=\sigma_{\varepsilon}^{2}, \\
& \mathrm{E}\left[\xi_{t}^{b} \xi_{t}^{b^{\prime}}\right]=\Xi^{b b}, \\
& \mathrm{E}\left[\xi_{t}^{a} \xi_{t}^{a \prime}\right]=\Xi^{a a}, \\
& \mathrm{E}\left[\xi_{t}^{b} \xi_{t}^{a \prime}\right]=\mathrm{E}\left[\xi_{t}^{a} \xi_{t}^{b^{\prime}}\right]=\Xi^{b a}=\Xi^{a b},
\end{aligned}
$$


where the $(N \times N)$ matrices $\Xi^{a a}, \Xi^{b b}, \Xi^{b a}$ and $\Xi^{a b}$ are all diagonal. All other moments are zero. Given these assumptions on the shocks, the unconditional covariance matrix will have the structure

$$
\widetilde{\Omega}=\left[\begin{array}{cc}
\sigma_{\varepsilon}^{2} l l^{\prime}+\Xi^{b b} & \sigma_{\varepsilon}^{2} l l^{\prime}+\Xi^{b a} \\
\sigma_{\varepsilon}^{2} \imath l^{\prime}+\Xi^{a b} & \sigma_{\varepsilon}^{2} \imath l^{\prime}+\Xi^{a a}
\end{array}\right] .
$$

The elements in $\Xi^{a a}, \Xi^{b b}$ and $\Xi^{b a}$ provide us with plausible sizes of dealer specific shocks.

With an appropriate size for a shock we can determine the nonlinear impulse responses. For this we follow the approach of Koop et al. (1996), who consider generalized impulse response functions (GI). These GI are dependent on the state of system $Y_{t-1}$, and the size and direction of the shock $\left(v_{t}\right)$. The generalized impulse response function is defined as

$$
G I\left(k, v_{t}, Y_{t-1}\right)=\mathrm{E}\left[y_{t+k} \mid v_{t}, Y_{t-1}\right]-\mathrm{E}\left[y_{t+k} \mid Y_{t-1}\right] \text { for } k=0,1, \ldots, K,
$$

where $K$ is the number of periods considered. The state of the system $Y_{t}$ contains the current bid and ask quotes $y_{t}=\left(b_{t}^{\prime} a_{t}^{\prime}\right)^{\prime}$, the inside quotes $i q^{a}=\min \left(a_{t}\right), i q_{t}^{b}=\max \left(b_{t}\right)$ and the inside indicators $I_{i t}^{a}=\mathbf{I}\left(a_{i t}=i q_{t}^{a}\right), I_{i t}^{b}=\mathbf{I}\left(b_{i t}=i q_{t}^{b}\right)$. The series of conditional expectations $\mathrm{E}\left[y_{t+k} \mid v_{t}, Y_{t-1}\right]$ defines the expected path of quotes conditional on the shock $v_{t}$ and conditional on a specific history. The conditional expectation $\mathrm{E}\left[y_{t+k} \mid Y_{t-1}\right]$ leads to the expected path conditional only on the specific history. This is also called the baseline. To arrive at unconditional nonlinear impulse responses we can integrate over all possible shocks and all possible histories.

For the present setting we are interested in specific shocks and histories. For a "bid" shock to dealer $i$ we set all elements of $v_{t}$ equal to zero except the two related to the bid and ask of dealer $i$, which are

$$
\begin{aligned}
& v_{i, t}= \pm \sqrt{\Xi_{i i}^{b b}}, \\
& v_{i+N, t}=\frac{\Xi_{i i}^{a b}}{\Xi_{i i}^{b b}} v_{i, t} .
\end{aligned}
$$

The "ask" shock is defined analogously.

To construct the baseline we integrate out all possible paths given a specific history. We start with a specific initial situation $Y_{t-1}$, e.g. a specific dealer at the inside, and then simulate the possible paths from this initial situation using model (1). In the simulation the inside quotes $i q_{t}$ and inside dummies $I_{t}$ are determined endogenously. The best bid is the maximum of the vector $b_{t}$, with the maximum taken over the $N$ dealers in the model. In this respect we differ slightly from the empirical model, in which the inside quotes were the best quotes over all dealers in the market. Since we include the most active dealers, the difference is very small, as one of these dealers is virtually always at the inside. Therefore, we always have that at least one of the elements of $I_{t}^{a}$ and $I_{t}^{b}$ is equal to one.

In the data quotes are issued at a discrete price grid and multiple dealers can be (and often are) at the inside. When randomly drawing error terms in the simulation, however, quotes become continuous, so that only one dealer will be at the inside. Therefore, we define a dealer to be at the inside (i.e. the respective inside dummy is equal to one) if her quote is within the range of half a tick size from our simulated inside. In this way multiple dealers can be at the inside simultaneously.

Simulation of the error terms $\eta_{t}$ is subject to the condition that at every point in time and for each dealer the ask quote must always be above the bid quote. A second condition on the simulated shocks is that they respect the conditional covariances depending on which dealer is at the inside. For these reasons we do not draw $\eta_{t}$ from a normal distribution, but prefer a bootstrap approach.

We simulate the system $(K+1)$ steps ahead by conditionally bootstrapping the innovation terms from our estimated model. The bootstrap is conditional since we draw from the empirical error terms $\hat{\eta}_{t}$ in such a way that spreads remain positive at all times. If some draw $\hat{\eta}_{t}$ would lead to a violation of strictly positive spreads, this draw is rejected and a new error vector is drawn. A second reason for doing a conditional bootstrap is the regime-dependent heteroskedasticity that may be present in the innovation terms. The distribution of the innovation term could be different depending on whether dealer $i$ would be at the inside or not. When dealer $i$ is at the inside in the simulation, we draw from the set of errors where dealer $i$ was at the inside in the data. However, to perform this conditional bootstrap correctly we would have to draw from the error term of our model conditional on the full state the model is in. In our empirical model we consider five dealers, and therefore 10! permutations of who is at the inside bid or ask. If at some point in the simulation dealers 
1 and 2 are at the inside ask, and dealers 2 and 4 are at the inside bid, we would have to condition on this complete event. Since the number of possible states by far exceeds the number of observations, this is empirically not feasible. To guarantee that each draw comes from a large set of shocks we would in the example draw from the set where either one or both of dealers 1 and 2 are at the inside ask, and either one or both of dealers 2 and 4 is at the inside bid. The conditional bootstrap subject to the inequality restrictions on bid and ask quotes introduces further non-linearity in the system.

When the baseline has been set conditional on the initial situation we can apply a one standard deviation shock with the size determined by our covariance matrix decomposition. The system is simulated again with the conditional bootstrap and the final generalized impulse response function $G I(\cdot)$ is calculated by subtracting the baseline from the shocked system.

\section{Data}

Nasdaq dealer quotes are obtained from the Nastraq data set provided by Nasdaq. This data set includes all transactions, dealer quotes and inside quotes issued at the Nasdaq trading system. Since we focus on dealer behavior we only consider the quote data in this paper. The data set contains time stamped quotes (to the nearest second) together with the identity of the market maker. Our sample runs from 1st February 1999 until 31st July 1999, giving us a total of 124 trading days. Huang (2002) uses a similar data set, but for different months. From the data set we select 20 companies that had the highest average trading volume over this period. Stock names and ticker symbols are reported in the Appendix in Table A.1.

When studying the dynamics of quotes issued on the NYSE, Engle and Patton (2004) include variables to capture the diurnality. They find that the diurnality is insignificant apart from the opening 30 mins. Chung and Zhao (2003) show that the intraday spread pattern of Nasdaq stocks has become similar to the intraday spread pattern for NYSE stocks. In our model we do not include variables to capture the diurnality pattern, but we exclude the first twenty minutes of the trading day. We therefore consider the trading day from 9.20 a.m until 4.00 p.m. Not considering the first 20 mins also circumvents the problem of a dealer not having posted a firm quote to the system yet.

Table 1

Summary statistics on spreads

\begin{tabular}{|c|c|c|c|c|c|c|c|}
\hline Stock & No. of days & IQ & Island & Instinet & MM1 & MM2 & MM3 \\
\hline AAPL & 124 & 0.0794 & 0.465 & 0.487 & 0.483 & 0.500 & 0.562 \\
\hline AMAT & 124 & 0.0772 & 0.217 & 0.327 & 0.634 & 0.656 & 0.540 \\
\hline $\mathrm{AMGN}^{*}$ & 121 & 0.108 & 1.560 & 1.470 & 0.750 & 0.596 & 0.700 \\
\hline AMZN & 120 & 0.145 & 0.357 & 0.832 & 1.296 & 4.411 & 1.742 \\
\hline ATHM ${ }^{*}$ & 122 & 0.176 & 0.729 & 1.836 & 1.180 & 2.316 & 1.904 \\
\hline CMGI $^{*}$ & 123 & 0.257 & 0.654 & 3.485 & 2.534 & 1.838 & 2.564 \\
\hline COMS & 123 & 0.0667 & 0.167 & 0.166 & 0.260 & 0.296 & 0.263 \\
\hline CPWR $^{*}$ & 121 & 0.0831 & 0.623 & 1.613 & 0.570 & 0.848 & 0.992 \\
\hline $\mathrm{CSCO}^{*}$ & 123 & 0.0754 & 0.184 & 0.246 & 0.566 & 0.847 & 0.655 \\
\hline DELL $^{*}$ & 123 & 0.0654 & 0.109 & 0.137 & 0.452 & 0.378 & 0.289 \\
\hline EGRP* & 122 & 0.111 & 0.273 & 0.694 & 0.603 & 0.669 & 0.513 \\
\hline INTC $^{*}$ & 123 & 0.0707 & 0.207 & 0.167 & 0.464 & 0.531 & 0.475 \\
\hline MSFT $^{*}$ & 123 & 0.0722 & 0.187 & 0.212 & 0.480 & 0.535 & 0.449 \\
\hline NOVL & 124 & 0.0687 & 0.306 & 0.627 & 0.305 & 0.413 & 0.256 \\
\hline NXTL & 118 & 0.0760 & 0.898 & 1.345 & 0.505 & 0.637 & 0.379 \\
\hline ORCL & 123 & 0.0666 & 0.142 & 0.246 & 0.336 & 0.439 & 0.235 \\
\hline PSFT & 123 & 0.0683 & 0.209 & 0.284 & 0.276 & 0.359 & 0.270 \\
\hline SUNW* & 123 & 0.0807 & 0.313 & 0.315 & 0.661 & 0.926 & 0.698 \\
\hline WCOM & 124 & 0.0743 & 0.362 & 0.222 & 0.585 & 0.437 & 0.781 \\
\hline YHOO* & 123 & 0.169 & 0.427 & 0.821 & 1.324 & 2.640 & 2.689 \\
\hline
\end{tabular}

This table reports average spreads for the firms in our sample. Data is from the period February 1999 to August 1999. Ticker symbols with an asterisk had a stock split occurring within the sample period. Number of days indicates the days without recording errors or other data issues and are the number of days used for our analysis. We report average spreads for the inside quote and dealer quotes in absolute terms (dollar spreads). 



Fig. 1. Average spreads for Amgen and Intel per dealer. This figure shows average dollar spreads per intra-daily interval over the whole sample periods for the stock Amgen and Intel (9.50 a.m.-4 p.m.).

Dealers are ranked on their quoting frequency. Quoting activity for ECNs and the top dealer are substantially larger than for the other dealers. From this ranking we extract the top two ECNs (Island and Instinet) and the top three market makers for each stock. For these five dealers (we refer to dealers being both ECNs and market makers) we observe quotes as well as inside quote (best bid and ask quote). We remove all days where a dealer posts less than 30 quotes. Next, we correct for stock splits by multiplying the data previous to the stock split with the ratio of the stock split. We include a dummy later on in our model for the stock split that has taken place. Finally, we compare all the dealer quotes with the inside quote and replace all quotes that deviate more than $\$ 5$ from the inside quote, by the previous quote. We make this correction since a dealer always has to trade at the quotes she issued. Whenever a dealer does not want to trade, she will set her quote far away from the inside to prevent this quote from being hit. Since a non-willingness to trade does not add to the price discovery process, we do not take these quotes into our model. For zero quotes we follow the same procedure.

We sample quotes at $120 \mathrm{~s}$ intervals. At this sampling frequency we hardly encounter missing observations or stale quotes. We deviate from Huang (2002), who pools dealers into groups. Our interest is in explaining individual dealer behavior. Moreover, Schultz (2003) shows that stocks are dominated by only few market makers, emphasizing the difference among individual market makers.

In Table 1 we report some summary statistics for our sample. From this table we see that spread patterns differ substantially among the different stocks and dealers. For some stocks spreads are smaller for the market makers than for the ECNs (AMGN), for other we observe the opposite (INTC). This might indicate that although ECNs are taking over market share from Nasdaq, they mainly focus on specific stocks traded at Nasdaq. Another interesting result is 
Table 2

Fraction of quotes at the inside for all dealers

\begin{tabular}{|c|c|c|c|c|c|c|c|c|c|c|}
\hline \multirow[t]{2}{*}{ Stock } & \multicolumn{2}{|l|}{ Island } & \multicolumn{2}{|c|}{ Instinet } & \multicolumn{2}{|l|}{ MM1 } & \multicolumn{2}{|l|}{ MM2 } & \multicolumn{2}{|l|}{ MM3 } \\
\hline & bid & ask & bid & ask & bid & ask & bid & ask & bid & ask \\
\hline AAPL & 0.392 & 0.428 & 0.391 & 0.434 & 0.177 & 0.177 & 0.153 & 0.162 & 0.135 & 0.166 \\
\hline AMAT & 0.594 & 0.658 & 0.408 & 0.417 & 0.105 & 0.111 & 0.082 & 0.079 & 0.184 & 0.158 \\
\hline AMGN & 0.284 & 0.325 & 0.382 & 0.408 & 0.106 & 0.095 & 0.198 & 0.168 & 0.144 & 0.115 \\
\hline AMZN & 0.543 & 0.597 & 0.287 & 0.276 & 0.048 & 0.045 & 0.029 & 0.035 & 0.085 & 0.059 \\
\hline ATHM & 0.407 & 0.447 & 0.351 & 0.368 & 0.136 & 0.111 & 0.069 & 0.050 & 0.098 & 0.076 \\
\hline CMGI & 0.516 & 0.550 & 0.212 & 0.216 & 0.099 & 0.094 & 0.142 & 0.136 & 0.071 & 0.061 \\
\hline COMS & 0.572 & 0.598 & 0.608 & 0.610 & 0.330 & 0.269 & 0.288 & 0.240 & 0.346 & 0.261 \\
\hline CPWR & 0.347 & 0.368 & 0.349 & 0.472 & 0.122 & 0.126 & 0.104 & 0.122 & 0.054 & 0.059 \\
\hline $\mathrm{CSCO}$ & 0.607 & 0.646 & 0.519 & 0.494 & 0.143 & 0.105 & 0.131 & 0.117 & 0.068 & 0.048 \\
\hline DELL & 0.708 & 0.744 & 0.637 & 0.646 & 0.277 & 0.239 & 0.275 & 0.281 & 0.221 & 0.182 \\
\hline EGRP & 0.539 & 0.567 & 0.323 & 0.314 & 0.196 & 0.157 & 0.220 & 0.179 & 0.241 & 0.182 \\
\hline INTC & 0.570 & 0.627 & 0.534 & 0.550 & 0.195 & 0.180 & 0.166 & 0.175 & 0.203 & 0.193 \\
\hline MSFT & 0.595 & 0.640 & 0.574 & 0.574 & 0.142 & 0.134 & 0.132 & 0.112 & 0.139 & 0.170 \\
\hline NOVL & 0.500 & 0.487 & 0.584 & 0.582 & 0.231 & 0.240 & 0.143 & 0.155 & 0.348 & 0.280 \\
\hline NXTL & 0.284 & 0.346 & 0.534 & 0.570 & 0.137 & 0.170 & 0.123 & 0.155 & 0.213 & 0.199 \\
\hline ORCL & 0.645 & 0.688 & 0.613 & 0.599 & 0.267 & 0.263 & 0.272 & 0.280 & 0.376 & 0.374 \\
\hline PSFT & 0.498 & 0.465 & 0.491 & 0.507 & 0.368 & 0.286 & 0.303 & 0.209 & 0.321 & 0.302 \\
\hline SUNW & 0.499 & 0.579 & 0.471 & 0.476 & 0.098 & 0.072 & 0.079 & 0.071 & 0.119 & 0.126 \\
\hline WCOM & 0.468 & 0.541 & 0.542 & 0.540 & 0.125 & 0.109 & 0.213 & 0.176 & 0.065 & 0.084 \\
\hline
\end{tabular}

Row sums can add to more than one, since several dealers can be at the inside simultaneously.

that, although the ECNs are in general most efficient with their quotes, there is still a big difference between their spreads and the inside spread. This is confirmed for the stocks of Amgen and Intel in Fig. 1, where we see that ECN spreads are relatively large compared to the spread for the inside quotes. These two stocks are selected because they are two representative cases for the more liquid stocks (INTC), where ECNs have smaller spreads than market makers, and less liquid stocks (AMGN), where market makers have the smaller spreads. Therefore, these two stocks will be used as examples throughout the remainder of the paper.

As we excluded the first 20 mins of the day, we see that the intradaily pattern is quite stable and that we do not observe a strong U-shaped pattern over the day. This is in line with the findings of Chan et al. (1995) who observe that the U-shaped pattern for Nasdaq stocks is much smaller than for NYSE listed stocks. From these graphs we can also infer that the inside quote is very stable over the day. Table 2 reports the fraction of times that dealers are at the inside. We find that overall ECNs are at the inside most of the time, which is in line with Huang (2002).

\section{Results}

In this section we present the results of the model proposed in Section 2. We first report the parameter estimates of the nonlinear model and the various tests proposed in Section 2. Next we discuss the nonlinear impulse response functions for two selected stocks from the sample, AMGN and INTC. Finally, we comment on the linear model as proposed by Hasbrouck (1991) by comparing the linear impulse responses with the nonlinear impulse responses.

\subsection{Estimation results}

We start the discussion of the results by testing the nonlinear model against the linear VECM. Wald statistics per stock are computed for the hypothesis $\Gamma=0$ and for the restrictions in (4) and are reported in Table 3 .

The addition of inside quotes leads to a significant improvement of the model for all twenty stocks. The inside dummies are all significant at a $1 \%$ level and contribute strongly to the nonlinearity. For 14 of the 20 stocks we also reject the linearity restrictions on $\Psi$ and $\theta$ at the $1 \%$ level and for 16 stocks at the $5 \%$ level. The average $R$-squared per stock ranges between 0.11 and 0.21 . This fit also differs per dealers (not reported), where the average fit for Island equals 0.18 , for Instinet 0.19 , MM1 0.22 and MM2 and MM3 both 0.13 . 
Table 3

Statistics for the nonlinear model

\begin{tabular}{|c|c|c|c|c|c|c|c|}
\hline Linear VECM & $\Gamma$ & & $\bar{R}^{2}$ & Linear VECM & $\Gamma$ & & $\bar{R}^{2}$ \\
\hline & $\chi^{2}(20)$ & $\chi^{2}(100)$ & & & $\chi^{2}(20)$ & $\chi^{2}(100)$ & \\
\hline AAPL & 111.55 & 1238.0 & 0.16 & EGRP & 39.56 & 343.79 & 0.16 \\
\hline AMAT & $\mathbf{5 7 . 3 0}$ & 1397.9 & 0.18 & INTC & 35.78 & 499.71 & 0.18 \\
\hline AMGN & 117.40 & 1690.2 & 0.15 & MSFT & 86.96 & 696.34 & 0.18 \\
\hline AMZN & 34.85 & 480.83 & 0.12 & NOVL & 23.50 & 1174.2 & 0.16 \\
\hline ATHM & 37.61 & 605.32 & 0.18 & NXTL & 72.23 & 1533.7 & 0.15 \\
\hline CMGI & 67.58 & 580.54 & 0.20 & ORCL & 56.79 & 711.10 & 0.13 \\
\hline COMS & 44.57 & 747.46 & 0.17 & PSFT & 123.09 & 802.91 & 0.18 \\
\hline CPWR & 76.13 & 1133.2 & 0.15 & SUNW & 59.26 & 1378.7 & 0.17 \\
\hline $\mathrm{CSCO}$ & 22.36 & 980.68 & 0.19 & WCOM & 29.97 & 1302.9 & 0.21 \\
\hline DELL & 21.66 & 698.27 & 0.18 & YHOO & 51.77 & 666.57 & 0.14 \\
\hline
\end{tabular}

This table reports tests of the nonlinear model. We report the Wald statistic for the restrictions (4) that reduce the dynamics to the linear VECM, the Wald statistic for the coefficient matrix of the inside dummies in (1). Entries in bold face indicate significance at the $1 \%$ level. We also report the average $R$-squared of the 10 equations in the system.

Table 4

Matrix of median coefficients for inside dummies $(\Gamma)$

\begin{tabular}{|c|c|c|c|c|c|c|c|c|c|c|}
\hline \multirow[b]{2}{*}{$\Delta b_{t}$} & \multicolumn{5}{|l|}{$I_{t-1}^{b}$} & \multicolumn{5}{|l|}{$I_{t-1}^{a}$} \\
\hline & ISLD & INST & MM1 & MM2 & MM3 & ISLD & INST & MM1 & MM2 & MM3 \\
\hline ISLD & $\begin{array}{l}0 \\
(12)\end{array}$ & $\begin{array}{l}0.021 \\
(11)\end{array}$ & $\begin{array}{l}-0.002 \\
\text { (1) }\end{array}$ & $\begin{array}{l}0.001 \\
(1)\end{array}$ & $\begin{array}{l}-0.006 \\
(2)\end{array}$ & $\begin{array}{l}-0.026 \\
(13)\end{array}$ & $\begin{array}{l}-0.027 \\
(13)\end{array}$ & $\begin{array}{l}0 \\
(1)\end{array}$ & $\begin{array}{l}0.006 \\
(0)\end{array}$ & $\begin{array}{l}-0.001 \\
\text { (1) }\end{array}$ \\
\hline INST & $\begin{array}{l}0.031 \\
(12)\end{array}$ & $\begin{array}{l}-0.038 \\
(13)\end{array}$ & $\begin{array}{l}-0.002 \\
(0)\end{array}$ & $\begin{array}{l}0.004 \\
(1)\end{array}$ & $\begin{array}{l}-0.003 \\
\text { (1) }\end{array}$ & $\begin{array}{l}-0.034 \\
(15)\end{array}$ & $\begin{array}{l}-0.024 \\
(10)\end{array}$ & $\begin{array}{l}-0.006 \\
(0)\end{array}$ & $\begin{array}{l}0.002 \\
(0)\end{array}$ & $\begin{array}{l}0.001 \\
(1)\end{array}$ \\
\hline MM1 & $\begin{array}{l}0.026 \\
(15)\end{array}$ & $\begin{array}{l}0.016 \\
(10)\end{array}$ & $\begin{array}{l}-0.051 \\
(14)\end{array}$ & $\begin{array}{l}0.002 \\
(3)\end{array}$ & $\begin{array}{l}-0.007 \\
(2)\end{array}$ & $\begin{array}{l}-0.028 \\
(16)\end{array}$ & $\begin{array}{l}-0.012 \\
(6)\end{array}$ & $\begin{array}{l}-0.013 \\
(4)\end{array}$ & $\begin{array}{l}0.002 \\
(0)\end{array}$ & $\begin{array}{l}0.006 \\
(1)\end{array}$ \\
\hline MM2 & $\begin{array}{l}0.022 \\
(12)\end{array}$ & $\begin{array}{l}0.016 \\
(9)\end{array}$ & $\begin{array}{l}0.005 \\
(0)\end{array}$ & $\begin{array}{l}-0.075 \\
(18)\end{array}$ & $\begin{array}{l}-0.003 \\
(1)\end{array}$ & $\begin{array}{l}-0.027 \\
(15)\end{array}$ & $\begin{array}{l}-0.015 \\
(8)\end{array}$ & $\begin{array}{l}-0.001 \\
(0)\end{array}$ & $\begin{array}{l}0.003 \\
(3)\end{array}$ & $\begin{array}{l}0.006 \\
(0)\end{array}$ \\
\hline MM3 & $\begin{array}{l}0.034 \\
(18)\end{array}$ & $\begin{array}{l}0.020 \\
(13)\end{array}$ & $\begin{array}{l}-0.001 \\
(0)\end{array}$ & $\begin{array}{l}0.002 \\
(5)\end{array}$ & $\begin{array}{l}-0.063 \\
(18)\end{array}$ & $\begin{array}{l}-0.037 \\
(19)\end{array}$ & $\begin{array}{l}-0.019 \\
(14)\end{array}$ & $\begin{array}{l}0.001 \\
(1)\end{array}$ & $\begin{array}{l}0.001 \\
(0)\end{array}$ & $\begin{array}{l}0.022 \\
(12)\end{array}$ \\
\hline$\Delta a_{t}$ & & & & & & & & & & \\
\hline ISLD & $\begin{array}{l}0.023 \\
(12)\end{array}$ & $\begin{array}{l}0.014 \\
(11)\end{array}$ & $\begin{array}{l}0.003 \\
(0)\end{array}$ & $\begin{array}{l}0.002 \\
(0)\end{array}$ & $\begin{array}{l}-0.002 \\
(0)\end{array}$ & $\begin{array}{l}-0.013 \\
(11)\end{array}$ & $\begin{array}{l}-0.019 \\
(8)\end{array}$ & $\begin{array}{l}0.003 \\
(1)\end{array}$ & $\begin{array}{l}0.001 \\
(0)\end{array}$ & $\begin{array}{l}0.002 \\
(1)\end{array}$ \\
\hline INST & $\begin{array}{l}0.028 \\
(15)\end{array}$ & $\begin{array}{l}0.014 \\
(8)\end{array}$ & $\begin{array}{l}0.003 \\
(0)\end{array}$ & $\begin{array}{l}0.001 \\
(0)\end{array}$ & $\begin{array}{l}-0.007 \\
(0)\end{array}$ & $\begin{array}{l}-0.030 \\
(11)\end{array}$ & $\begin{array}{l}0.021 \\
(10)\end{array}$ & $\begin{array}{l}-0.003 \\
(1)\end{array}$ & $\begin{array}{l}0 \\
(0)\end{array}$ & $\begin{array}{l}0.005 \\
(0)\end{array}$ \\
\hline MM1 & $\begin{array}{l}0.026 \\
(14)\end{array}$ & $\begin{array}{l}0.014 \\
(6)\end{array}$ & $\begin{array}{l}0.009 \\
(4)\end{array}$ & $\begin{array}{l}0.003 \\
(0)\end{array}$ & $\begin{array}{l}-0.002 \\
(0)\end{array}$ & $\begin{array}{l}-0.017 \\
(10)\end{array}$ & $\begin{array}{l}-0.012 \\
(5)\end{array}$ & $\begin{array}{l}0.047 \\
(16)\end{array}$ & $\begin{array}{l}0.001 \\
(1)\end{array}$ & $\begin{array}{l}0.010 \\
(1)\end{array}$ \\
\hline MM2 & $\begin{array}{l}0.021 \\
(12)\end{array}$ & $\begin{array}{l}0.011 \\
(5)\end{array}$ & $\begin{array}{l}0.003 \\
(1)\end{array}$ & $\begin{array}{l}0.006 \\
(4)\end{array}$ & $\begin{array}{l}-0.006 \\
(0)\end{array}$ & $\begin{array}{l}-0.022 \\
(13)\end{array}$ & $\begin{array}{l}-0.018 \\
(9)\end{array}$ & $\begin{array}{l}-0.005 \\
(0)\end{array}$ & $\begin{array}{l}0.085 \\
(19)\end{array}$ & $\begin{array}{l}0.005 \\
(1)\end{array}$ \\
\hline MM3 & $\begin{array}{l}0.033 \\
(18)\end{array}$ & $\begin{array}{l}0.019 \\
(14)\end{array}$ & $\begin{array}{l}-0.004 \\
(0)\end{array}$ & $\begin{array}{l}0.001 \\
(1)\end{array}$ & $\begin{array}{l}-0.030 \\
(13)\end{array}$ & $\begin{array}{l}-0.036 \\
(19)\end{array}$ & $\begin{array}{l}-0.017 \\
(13)\end{array}$ & $\begin{array}{l}0.003 \\
(0)\end{array}$ & $\begin{array}{l}0 \\
(0)\end{array}$ & $\begin{array}{l}0.080 \\
(20)\end{array}$ \\
\hline
\end{tabular}

This table reports median coefficients for the Inside Dummies in the nonlinear model (1). The number of firms for which coefficients are significant at the $1 \%$ level are reported in parentheses.

Table 4 presents the median coefficients of the lagged inside dummies for all stocks in the sample. We first consider the effects of the change in a quote, when that quote is at the inside (the diagonal of the top left and the bottom right quadrant). For the individual dealers (MM1, MM2, MM3) the effect is clear cut. If they are at the inside bid, the negative coefficient implies that they tend to decrease their bid quote, moving away from the inside. When they are at the inside ask they are also expected to move away from the inside, as indicated by the positive coefficients at the diagonal for 
Table 5

Matrix of median coefficients for lagged quotes $(\Phi)$

\begin{tabular}{|c|c|c|c|c|c|c|c|c|c|c|}
\hline \multirow[b]{2}{*}{$\Delta b_{t}$} & \multicolumn{5}{|l|}{$\Delta b_{t-1}$} & \multicolumn{5}{|l|}{$\Delta a_{t-1}$} \\
\hline & ISLD & INST & MM1 & MM2 & MM3 & ISLD & INST & MM1 & MM2 & MM3 \\
\hline ISLD & $\begin{array}{l}-0.101 \\
(18)\end{array}$ & $\begin{array}{l}0.004 \\
(0)\end{array}$ & $\begin{array}{l}-0.001 \\
(0)\end{array}$ & $\begin{array}{l}-0.003 \\
\text { (1) }\end{array}$ & $\begin{array}{l}-0.001 \\
(0)\end{array}$ & $\begin{array}{l}0.038 \\
(15)\end{array}$ & $\begin{array}{l}0.013 \\
(2)\end{array}$ & $\begin{array}{l}0.001 \\
(0)\end{array}$ & $\begin{array}{l}0.010 \\
(0)\end{array}$ & $\begin{array}{l}0.015 \\
(0)\end{array}$ \\
\hline INST & $\begin{array}{l}0.008 \\
(1)\end{array}$ & $\begin{array}{l}-0.129 \\
(17)\end{array}$ & $\begin{array}{l}0.006 \\
(0)\end{array}$ & $\begin{array}{l}0.002 \\
(0)\end{array}$ & $\begin{array}{l}0.001 \\
(0)\end{array}$ & $\begin{array}{l}0.027 \\
(10)\end{array}$ & $\begin{array}{l}0.015 \\
(3)\end{array}$ & $\begin{array}{l}0.010 \\
(2)\end{array}$ & $\begin{array}{l}0.009 \\
(1)\end{array}$ & $\begin{array}{l}0.016 \\
(1)\end{array}$ \\
\hline MM1 & $\begin{array}{l}0 \\
(1)\end{array}$ & $\begin{array}{l}0.006 \\
(1)\end{array}$ & $\begin{array}{l}-0.105 \\
(20)\end{array}$ & $\begin{array}{l}0 \\
(5)\end{array}$ & $\begin{array}{l}-0.004 \\
(2)\end{array}$ & $\begin{array}{l}0.015 \\
(5)\end{array}$ & $\begin{array}{l}0.014 \\
(6)\end{array}$ & $\begin{array}{l}0.024 \\
(6)\end{array}$ & $\begin{array}{l}0.015 \\
(2)\end{array}$ & $\begin{array}{l}0.020 \\
(2)\end{array}$ \\
\hline MM2 & $\begin{array}{l}0.010 \\
(2)\end{array}$ & $\begin{array}{l}0.012 \\
(2)\end{array}$ & $\begin{array}{l}0.008 \\
(2)\end{array}$ & $\begin{array}{l}-0.108 \\
(19)\end{array}$ & $\begin{array}{l}0.013 \\
(3)\end{array}$ & $\begin{array}{l}0.032 \\
(8)\end{array}$ & $\begin{array}{l}0.017 \\
(7)\end{array}$ & $\begin{array}{l}0.005 \\
(1)\end{array}$ & $\begin{array}{l}0.024 \\
(7)\end{array}$ & $\begin{array}{l}0.003 \\
(0)\end{array}$ \\
\hline MM3 & $\begin{array}{l}0.016 \\
(5)\end{array}$ & $\begin{array}{l}0.014 \\
(8)\end{array}$ & $\begin{array}{l}0.019 \\
(6)\end{array}$ & $\begin{array}{l}0.005 \\
(4)\end{array}$ & $\begin{array}{l}-0.097 \\
(15)\end{array}$ & $\begin{array}{l}0.028 \\
(10)\end{array}$ & $\begin{array}{l}0.016 \\
(7)\end{array}$ & $\begin{array}{l}0.011 \\
(2)\end{array}$ & $\begin{array}{l}0.006 \\
(1)\end{array}$ & $\begin{array}{l}0.019 \\
(3)\end{array}$ \\
\hline$\Delta a_{t}$ & & & & & & & & & & \\
\hline ISLD & $\begin{array}{l}0.033 \\
(13)\end{array}$ & $\begin{array}{l}0.013 \\
(4)\end{array}$ & $\begin{array}{l}0.008 \\
(1)\end{array}$ & $\begin{array}{l}0.004 \\
(0)\end{array}$ & $\begin{array}{l}0.004 \\
(0)\end{array}$ & $\begin{array}{l}-0.098 \\
(15)\end{array}$ & $\begin{array}{l}-0.004 \\
\text { (1) }\end{array}$ & $\begin{array}{l}-0.011 \\
(2)\end{array}$ & $\begin{array}{l}-0.001 \\
(0)\end{array}$ & $\begin{array}{l}-0.003 \\
(0)\end{array}$ \\
\hline INST & $\begin{array}{l}0.022 \\
(11)\end{array}$ & $\begin{array}{l}0.016 \\
(2)\end{array}$ & $\begin{array}{l}0.015 \\
(6)\end{array}$ & $\begin{array}{l}0.011 \\
(1)\end{array}$ & $\begin{array}{l}0.014 \\
(0)\end{array}$ & $\begin{array}{l}0.007 \\
(3)\end{array}$ & $\begin{array}{l}-0.133 \\
(19)\end{array}$ & $\begin{array}{l}-0.011 \\
(0)\end{array}$ & $\begin{array}{l}-0.004 \\
(0)\end{array}$ & $\begin{array}{l}0.002 \\
(1)\end{array}$ \\
\hline MM1 & $\begin{array}{l}0.014 \\
(5)\end{array}$ & $\begin{array}{l}0.012 \\
(5)\end{array}$ & $\begin{array}{l}0.025 \\
(8)\end{array}$ & $\begin{array}{l}0.011 \\
(3)\end{array}$ & $\begin{array}{l}0.029 \\
(7)\end{array}$ & $\begin{array}{l}-0.002 \\
\text { (1) }\end{array}$ & $\begin{array}{l}0.003 \\
(1)\end{array}$ & $\begin{array}{l}-0.127 \\
(20)\end{array}$ & $\begin{array}{l}-0.008 \\
(2)\end{array}$ & $\begin{array}{l}0.002 \\
(2)\end{array}$ \\
\hline MM2 & $\begin{array}{l}0.020 \\
(9)\end{array}$ & $\begin{array}{l}0.018 \\
(8)\end{array}$ & $\begin{array}{l}0.015 \\
(5)\end{array}$ & $\begin{array}{l}0.018 \\
(5)\end{array}$ & $\begin{array}{l}0.021 \\
(3)\end{array}$ & $\begin{array}{l}0.010 \\
(4)\end{array}$ & $\begin{array}{l}0.003 \\
(2)\end{array}$ & $\begin{array}{l}-0.005 \\
\text { (1) }\end{array}$ & $\begin{array}{l}-0.116 \\
(19)\end{array}$ & $\begin{array}{l}-0.004 \\
(1)\end{array}$ \\
\hline MM3 & $\begin{array}{l}0.018 \\
(8)\end{array}$ & $\begin{array}{l}0.015 \\
(6)\end{array}$ & $\begin{array}{l}0.019 \\
(7)\end{array}$ & $\begin{array}{l}0.007 \\
(4)\end{array}$ & $\begin{array}{l}0.027 \\
(6)\end{array}$ & $\begin{array}{l}0.023 \\
(6)\end{array}$ & $\begin{array}{l}0.011 \\
(4)\end{array}$ & $\begin{array}{l}-0.002 \\
\text { (2) }\end{array}$ & $\begin{array}{l}0.005 \\
(2)\end{array}$ & $\begin{array}{l}-0.096 \\
(17)\end{array}$ \\
\hline
\end{tabular}

This table reports median coefficients for the lagged quotes $(\Phi)$ in the nonlinear model (1). The number of firms for which coefficients are significant at the $1 \%$ level are reported in parentheses.

the ask dynamics. The estimates are significant for most stocks at the $1 \%$ level. The results are different for the two ECNs. Here the coefficients are less often significant and the median over all stocks is much closer to zero. The effects are particularly small to non-existent for Island.

There are several interesting cross-effects observed in the table. First, there is a positive and symmetric reaction of other dealers' bid and ask quotes (the first columns of each quadrant) to Island being at the inside bid. Dealers tend to raise both quotes with the same amount when Island is at the inside bid. A similar result is obtained when Island is at the inside ask, all other dealers tend to lower their quotes, again in a symmetric fashion. This is an indication of the importance of this ECN. For Instinet the results are similar, though less significant. On the other side of the spectrum we observe the reaction of the ECNs to market makers being at the inside. There is only a very small reaction of ECNs to market makers being at the inside, with only few significant coefficients.

In Table 5 we present the median coefficients of the AR(1) component. All coefficients along the main diagonal are negative. Hence, when a dealer raises a quote she is more inclined to lower that quote again in the next period. The magnitude of this effect is the same for all dealers. Furthermore, there are some cross effects present between the bid and ask of the same dealer, but most of the other cross effects are insignificant.

Table 6 presents the median coefficients of the error correction term. Again we observe a strong effect along the main diagonal, where all coefficients are negative and significant. Hence, all dealers adjust their quotes towards the respective inside quotes. Note that these coefficients get smaller in absolute terms for the less active dealers. This is in line with the fractions of time a dealer is at the inside as we observed in Table 2 and indicates that error correction effects are stronger for ECNs than for market makers. We hardly observe cross effects between bid and ask quotes of the same dealer, except for market maker 3, who has her other quote moving away from the inside (market maker 3 is often represented by the same market maker SLKC). This indicates that dealers only focus on the respective inside quote and do not consider the other inside quote. All other cross effects are mostly insignificant. 
Table 6

Matrix of median coefficients for error correction term $(\Psi)$

\begin{tabular}{|c|c|c|c|c|c|c|c|c|c|c|}
\hline \multirow[b]{2}{*}{$\Delta b_{t}$} & \multicolumn{5}{|c|}{$\left(b_{t-1}-l i q_{t-1}^{b}\right)$} & \multicolumn{5}{|c|}{$\left(a_{t-1}-l i q_{t-1}^{a}\right)$} \\
\hline & ISLD & INST & MM1 & MM2 & MM3 & ISLD & INST & MM1 & MM2 & MM3 \\
\hline ISLD & $\begin{array}{l}-0.604 \\
(20)\end{array}$ & $\begin{array}{l}0.021 \\
(9)\end{array}$ & $\begin{array}{l}0.031 \\
(11)\end{array}$ & $\begin{array}{l}0.014 \\
(5)\end{array}$ & $\begin{array}{l}0.011 \\
(4)\end{array}$ & $\begin{array}{l}-0.010 \\
(5)\end{array}$ & $\begin{array}{l}0.013 \\
(1)\end{array}$ & $\begin{array}{l}0.010 \\
(3)\end{array}$ & $\begin{array}{l}0.003 \\
(0)\end{array}$ & $\begin{array}{l}-0.005 \\
(2)\end{array}$ \\
\hline INST & $\begin{array}{l}0.024 \\
(3)\end{array}$ & $\begin{array}{l}-0.530 \\
(20)\end{array}$ & $\begin{array}{l}0.019 \\
(2)\end{array}$ & $\begin{array}{l}0.012 \\
(6)\end{array}$ & $\begin{array}{l}0.018 \\
(5)\end{array}$ & $\begin{array}{l}0.006 \\
(1)\end{array}$ & $\begin{array}{l}0.002 \\
(4)\end{array}$ & $\begin{array}{l}0 \\
(2)\end{array}$ & $\begin{array}{l}-0.004 \\
(0)\end{array}$ & $\begin{array}{l}-0.016 \\
(2)\end{array}$ \\
\hline MM1 & $\begin{array}{l}0.033 \\
(12)\end{array}$ & $\begin{array}{l}0.028 \\
(7)\end{array}$ & $\begin{array}{l}-0.553 \\
(20)\end{array}$ & $\begin{array}{l}0.023 \\
(13)\end{array}$ & $\begin{array}{l}0.017 \\
(9)\end{array}$ & $\begin{array}{l}0.009 \\
(3)\end{array}$ & $\begin{array}{l}0.003 \\
(3)\end{array}$ & $\begin{array}{l}-0.021 \\
(6)\end{array}$ & $\begin{array}{l}-0.004 \\
\text { (2) }\end{array}$ & $\begin{array}{l}-0.011 \\
(3)\end{array}$ \\
\hline MM2 & $\begin{array}{l}0.018 \\
(5)\end{array}$ & $\begin{array}{l}0.011 \\
(4)\end{array}$ & $\begin{array}{l}0.012 \\
(2)\end{array}$ & $\begin{array}{l}-0.241 \\
(19)\end{array}$ & $\begin{array}{l}0.010 \\
(3)\end{array}$ & $\begin{array}{l}0.003 \\
(0)\end{array}$ & $\begin{array}{l}0.004 \\
(1)\end{array}$ & $\begin{array}{l}-0.004 \\
\text { (4) }\end{array}$ & $\begin{array}{l}-0.021 \\
(9)\end{array}$ & $\begin{array}{l}-0.006 \\
(3)\end{array}$ \\
\hline MM3 & $\begin{array}{l}0.021 \\
(3)\end{array}$ & $\begin{array}{l}0.010 \\
(3)\end{array}$ & $\begin{array}{l}0 \\
(5)\end{array}$ & $\begin{array}{l}-0.002 \\
(4)\end{array}$ & $\begin{array}{l}-0.215 \\
(20)\end{array}$ & $\begin{array}{l}0.009 \\
(2)\end{array}$ & $\begin{array}{l}0.005 \\
(1)\end{array}$ & $\begin{array}{l}-0.009 \\
(5)\end{array}$ & $\begin{array}{l}-0.002 \\
(0)\end{array}$ & $\begin{array}{l}-0.086 \\
(16)\end{array}$ \\
\hline$\Delta a_{t}$ & & & & & & & & & & \\
\hline ISLD & $\begin{array}{l}-0.006 \\
(5)\end{array}$ & $\begin{array}{l}0.009 \\
(2)\end{array}$ & $\begin{array}{l}0.006 \\
(1)\end{array}$ & $\begin{array}{l}0.001 \\
(3)\end{array}$ & $\begin{array}{l}-0.002 \\
\text { (3) }\end{array}$ & $\begin{array}{l}-0.630 \\
(20)\end{array}$ & $\begin{array}{l}0.034 \\
(9)\end{array}$ & $\begin{array}{l}0.047 \\
(17)\end{array}$ & $\begin{array}{l}0.024 \\
(10)\end{array}$ & $\begin{array}{l}0.018 \\
(4)\end{array}$ \\
\hline INST & $\begin{array}{l}-0.004 \\
\text { (1) }\end{array}$ & $\begin{array}{l}0.007 \\
(2)\end{array}$ & $\begin{array}{l}-0.006 \\
(0)\end{array}$ & $\begin{array}{l}-0.001 \\
(1)\end{array}$ & $\begin{array}{l}-0.013 \\
(3)\end{array}$ & $\begin{array}{l}0.036 \\
(8)\end{array}$ & $\begin{array}{l}-0.486 \\
(20)\end{array}$ & $\begin{array}{l}0.045 \\
(14)\end{array}$ & $\begin{array}{l}0.017 \\
(9)\end{array}$ & $\begin{array}{l}0.021 \\
(8)\end{array}$ \\
\hline MM1 & $\begin{array}{l}0.002 \\
(2)\end{array}$ & $\begin{array}{l}0.002 \\
(0)\end{array}$ & $\begin{array}{l}-0.030 \\
(8)\end{array}$ & $\begin{array}{l}0 \\
(6)\end{array}$ & $\begin{array}{l}-0.024 \\
(11)\end{array}$ & $\begin{array}{l}0.069 \\
(19)\end{array}$ & $\begin{array}{l}0.040 \\
(15)\end{array}$ & $\begin{array}{l}-0.435 \\
(20)\end{array}$ & $\begin{array}{l}0.030 \\
(16)\end{array}$ & $\begin{array}{l}0.030 \\
(11)\end{array}$ \\
\hline MM2 & $\begin{array}{l}0.005 \\
(1)\end{array}$ & $\begin{array}{l}0 \\
(0)\end{array}$ & $\begin{array}{l}-0.012 \\
\text { (4) }\end{array}$ & $\begin{array}{l}-0.023 \\
(11)\end{array}$ & $\begin{array}{l}-0.008 \\
(5)\end{array}$ & $\begin{array}{l}0.025 \\
(8)\end{array}$ & $\begin{array}{l}0.015 \\
(6)\end{array}$ & $\begin{array}{l}0.024 \\
(9)\end{array}$ & $\begin{array}{l}-0.208 \\
(20)\end{array}$ & $\begin{array}{l}0.013 \\
(7)\end{array}$ \\
\hline MM3 & $\begin{array}{l}0.003 \\
(1)\end{array}$ & $\begin{array}{l}0.002 \\
(1)\end{array}$ & $\begin{array}{l}-0.009 \\
\text { (1) }\end{array}$ & $\begin{array}{l}-0.003 \\
\text { (3) }\end{array}$ & $\begin{array}{l}-0.079 \\
(18)\end{array}$ & $\begin{array}{l}0.012 \\
(3)\end{array}$ & $\begin{array}{l}0.016 \\
(6)\end{array}$ & $\begin{array}{l}0.009 \\
(7)\end{array}$ & $\begin{array}{l}0.007 \\
(6)\end{array}$ & $\begin{array}{l}-0.199 \\
(20)\end{array}$ \\
\hline
\end{tabular}

This table reports median coefficients for the error correction term $(\Psi)$ in the nonlinear model (1). The number of firms for which coefficients are significant at the $1 \%$ level are reported in parentheses.

Table 7

Median coefficients for the inside spread $(\theta)$

\begin{tabular}{llll}
\hline$\Delta b_{t}$ & $a i q_{t-1}-b i q_{t-1}$ & $\Delta a_{t}$ & $a i q_{t-1}-b i q_{t-1}$ \\
\hline ISLD & $0.305(17)$ & ISLD & $-0.135(10)$ \\
INST & $0.340(19)$ & INST & $-0.164(12)$ \\
MM1 & $0.205(17)$ & MM1 & $-0.066(5)$ \\
MM2 & $0.170(13)$ & MM2 & $-0.026(2)$ \\
MM3 & $0.121(7)$ & MM3 & $-0.004(5)$ \\
\hline
\end{tabular}

This table reports results for inside spread coefficients in model (1). We report median coefficients for $\theta$ and the number of firms for which $\theta$ is significant at the $1 \%$ level.

Table 7 reports the median coefficients on the inside spread. As can be seen from the signs of the coefficients (positive for bids and negative for asks) dealers adjust their quotes to keep spreads small. This adjustment is stronger for ECNs than for market makers. This confirms the notion that ECNs profit from keeping spreads small, whereas market makers could potentially profit from larger spreads. Therefore, ECNs are more inclined to keep spreads small than market makers. Another interesting result is that the coefficients on the changes in bids are always larger, in absolute terms, than the coefficients of the changes in the ask. Hence there is an asymmetric adjustment of dealer quotes to the size of the inside spread. Dealers are more inclined to raise the bid quote than to lower the ask quote.

The results presented above all indicate that bid and ask quotes display nonlinear features, with the strongest nonlinearity related to a dealer being at the inside or not. As being at the inside influences the dynamics of dealer quotes we are interested in whether it also affects second order moments. We perform a Breusch-Pagan test on (5) and (6) to test for regime-dependent heteroskedasticity. In Table 8 we present the results. We report the number of regressions for which the test statistic is significant at the 5\% level. The diagonal of this matrix represent the variance of each dealer's 
Table 8

Breusch Pagan test for regime dependent heteroscedasticity

\begin{tabular}{|c|c|c|c|c|c|c|c|c|c|c|}
\hline & $\eta_{1}^{b}$ & $\eta_{2}^{b}$ & $\eta_{3}^{b}$ & $\eta_{4}^{b}$ & $\eta_{5}^{b}$ & $\eta_{1}^{a}$ & $\eta_{2}^{a}$ & $\eta_{3}^{a}$ & $\eta_{4}^{a}$ & $\eta_{5}^{a}$ \\
\hline$\eta_{1}^{b}$ & 12 & - & - & - & - & - & - & - & - & - \\
\hline$\eta_{2}^{b}$ & 8 & 6 & - & - & - & 9 & - & - & - & - \\
\hline$\eta_{3}^{b}$ & 7 & 4 & 11 & - & - & 7 & 3 & - & - & - \\
\hline$\eta_{4}^{b}$ & 10 & 5 & 6 & 11 & - & 8 & 4 & 5 & - & - \\
\hline$\eta_{5}^{b}$ & 11 & 8 & 9 & 8 & 11 & 11 & 7 & 9 & 7 & - \\
\hline$\eta_{1}^{a}$ & 6 & - & - & - & - & 12 & - & - & - & - \\
\hline$\eta_{2}^{a}$ & 5 & 2 & - & - & - & 7 & 9 & - & - & - \\
\hline$\eta_{3}^{a}$ & 10 & 4 & 4 & - & - & 9 & 5 & 8 & - & - \\
\hline$\eta_{4}^{a}$ & 8 & 6 & 5 & 6 & - & 7 & 7 & 5 & 10 & - \\
\hline$\eta_{5}^{a}$ & 11 & 8 & 8 & 7 & 9 & 10 & 7 & 10 & 7 & 10 \\
\hline
\end{tabular}

This table reports the number of cases in which significant regime-dependent heteroskedasticity at the 5\% level was found. The main diagonal of the table shows this number for the variances using the regression

$$
\Omega_{i i, t+1}=\omega_{0 i}+\omega_{1 i} I_{i t}^{b}+\omega_{2 i} I_{i t}^{a}
$$

where $\Omega_{i i, t+1}$ is the bid or ask variance of dealer $i, I_{i t}^{b}$ is the inside dummy equal to 1 if the bid of dealer $i$ is at the inside and $I_{i t}^{a}$ the inside dummy equal to 1 if the ask of dealer $i$ is at the inside. All other elements show this number for the covariances, using the regression

$$
\Omega_{i j, t+1}=\lambda_{0 i j}+\lambda_{1 i j} I_{i t}^{b}+\lambda_{2 i j} I_{i t}^{a}+\lambda_{3 i j} I_{j t}^{b}+\lambda_{4 i j} I_{j t}^{a},
$$

where $\Omega_{i j, t+1}$ is the covariance between a particular quote of dealer $i$ and dealer $j$.

bid or ask quote and the off-diagonal the covariances. The results remain inconclusive. In about $50 \%$ of the cases we find a significant relationship between the variance of quote changes and the inside dummies. For the off-diagonal elements we find less significance. We remain inconclusive in this, but note that for some stocks in the sample this effect has a significant impact on the behavior of dealers.

As the results of this regime-dependent heteroskedasticity test remain inconclusive, we can motivate the unconditional decomposition proposed in (7). If regime-dependent heteroskedasticity was present, the decomposition in (7) has to take this into account and decompose the covariance matrix conditional on the state that it is. We impose the structure of the covariance matrix as in (9) on the empirical covariance matrix that we obtain from the regression. We use GMM to achieve this, by fitting the parameters in our restricted covariance matrix to the unrestricted sample covariance matrix, i.e. we use the $N(2 N+1)$ different orthogonality conditions in $E\left[\tilde{\Omega}-\eta_{t} \eta_{t}^{\prime}\right]=0$ to fit the $3 N+1$ parameters in $\tilde{\Omega}$.

We discuss results for AMGN and INTC in some detail and report the unrestricted covariance matrices in panel A of Tables 9 and 10, and show the restricted covariance matrices in panel B.

For AMGN we observe that the noise terms for the ECNs are much larger than for the market makers. In Table 2 we already found that for this relatively illiquid stock, ECNs had the larger spreads. Clearly, there is a lot of idiosyncratic noise around the dynamics of these ECNs. Another interesting result is the cross-covariance between ECNs. Although small compared to the variances, these are still twice the size of the common market part. A final remark is the correlation between the bid and ask quote for market maker 3. These error components are almost perfectly correlated.

Turning to the covariance matrix of Intel in Table 10 we observe the same thing for market maker 3. However, for this stock the market makers tend to have higher variances than the ECNs. Further, the cross-effects between ECNs have disappeared.

The fundamental noise in the market concerns the information common to all dealers. This can be considered as market wide information (public information) but is also due to time aggregation of dealer quotes (see Hasbrouck, 
Table 9

Covariance matrix of the nonlinear model for amgen

\begin{tabular}{|c|c|c|c|c|c|c|c|c|c|}
\hline \multicolumn{10}{|c|}{ Panel A: Unrestricted covariance matrix } \\
\hline 1.224 & 0.073 & 0.036 & 0.037 & 0.053 & 0.072 & 0.073 & 0.036 & 0.036 & 0.052 \\
\hline 0.073 & 0.587 & 0.036 & 0.034 & 0.046 & 0.062 & 0.082 & 0.029 & 0.033 & 0.044 \\
\hline 0.036 & 0.036 & 0.070 & 0.031 & 0.034 & 0.036 & 0.032 & 0.026 & 0.027 & 0.033 \\
\hline 0.037 & 0.034 & 0.031 & 0.053 & 0.037 & 0.035 & 0.032 & 0.026 & 0.035 & 0.036 \\
\hline 0.053 & 0.046 & 0.034 & 0.037 & 0.088 & 0.043 & 0.043 & 0.030 & 0.034 & 0.080 \\
\hline 0.072 & 0.062 & 0.036 & 0.035 & 0.043 & 0.864 & 0.060 & 0.032 & 0.031 & 0.043 \\
\hline 0.073 & 0.082 & 0.032 & 0.032 & 0.043 & 0.060 & 0.473 & 0.030 & 0.032 & 0.044 \\
\hline 0.036 & 0.029 & 0.026 & 0.026 & 0.030 & 0.032 & 0.030 & 0.073 & 0.028 & 0.030 \\
\hline 0.036 & 0.033 & 0.027 & 0.035 & 0.034 & 0.031 & 0.032 & 0.028 & 0.058 & 0.034 \\
\hline 0.052 & 0.044 & 0.033 & 0.036 & 0.080 & 0.043 & 0.044 & 0.030 & 0.034 & 0.087 \\
\hline \multicolumn{10}{|c|}{ Panel B: Restricted covariance matrix } \\
\hline 1.224 & 0.039 & 0.039 & 0.039 & 0.039 & 0.072 & 0.039 & 0.039 & 0.039 & 0.039 \\
\hline 0.039 & 0.587 & 0.039 & 0.039 & 0.039 & 0.039 & 0.082 & 0.039 & 0.039 & 0.039 \\
\hline 0.039 & 0.039 & 0.070 & 0.039 & 0.039 & 0.039 & 0.039 & 0.026 & 0.039 & 0.039 \\
\hline 0.039 & 0.039 & 0.039 & 0.053 & 0.039 & 0.039 & 0.039 & 0.039 & 0.035 & 0.039 \\
\hline 0.039 & 0.039 & 0.039 & 0.039 & 0.088 & 0.039 & 0.039 & 0.039 & 0.039 & 0.080 \\
\hline 0.072 & 0.039 & 0.039 & 0.039 & 0.039 & 0.864 & 0.039 & 0.039 & 0.039 & 0.039 \\
\hline 0.039 & 0.082 & 0.039 & 0.039 & 0.039 & 0.039 & 0.473 & 0.039 & 0.039 & 0.039 \\
\hline 0.039 & 0.039 & 0.026 & 0.039 & 0.039 & 0.039 & 0.039 & 0.073 & 0.039 & 0.039 \\
\hline 0.039 & 0.039 & 0.039 & 0.035 & 0.039 & 0.039 & 0.039 & 0.039 & 0.058 & 0.039 \\
\hline 0.039 & 0.039 & 0.039 & 0.039 & 0.080 & 0.039 & 0.039 & 0.039 & 0.039 & 0.087 \\
\hline
\end{tabular}

This table reports the unrestricted and restricted covariance matrix for the stock Amgen. The unrestricted covariance matrix is decomposed into a common factor (market-wide news) and an idiosyncratic dealer components and takes the form

$$
\widetilde{\Omega}=\left[\begin{array}{cc}
\sigma_{\varepsilon}^{2} l l^{\prime}+\Xi^{b b} & \sigma_{\varepsilon}^{2} l l^{\prime}+\Xi^{b a} \\
\sigma_{\varepsilon}^{2} l l^{\prime}+\Xi^{a b} & \sigma_{\varepsilon}^{2} l l^{\prime}+\Xi^{a a}
\end{array}\right],
$$

where $\sigma_{\varepsilon}^{2}$ represents the market-wide component and $\Xi^{b b}, \Xi^{b a}, \Xi^{a b}$ and $\Xi^{a a}$ are the dealer idiosyncratic components.

1995). With the exception of market maker 3 all correlations between private information in bid and ask quotes of individual dealers are close to zero. This is in line with Jang and Venkatesh (1991), who find that in most cases dealers adjust their quote only on one side of the market when they receive private information.

Although being very informative on the nature of the dealer, the main use of this decomposition is to provide us with parameters that indicate the size of the fundamental news and the idiosyncratic part, individual to every dealer. We need the sizes of these idiosyncratic parts to evaluate the impulse response functions of the nonlinear model.

\subsection{Impulse response functions}

After having determined reasonable shock sizes, we can now conduct experiments on dealer quote reactions to dealer specific shocks. We simulate the model 5000 times and use a time horizon of 20 steps which in our model represents 40 mins. Although the price discovery process will be much faster than 40 mins for most stocks, we perform this longterm simulation to check the stability of the system. With unrestricted estimates of the inside dummy effects $\Gamma I_{t}$ in (1), we cannot a priori guarantee that the model is stable. In all cases, i.e. all stocks and all shocks, we found that the long-term impact of a shock is finite and the same for all bids and asks. This confirms that the system behaves as a cointegrated system with a single common trend.

We consider four experiments of interest. The first experiment is a one standard deviation idiosyncratic shock for a specific dealer towards the inside quote, when all dealers start at average spreads. The shock is applied to one quote, bid or ask, where the other quote receives a shock with a size dependent on the correlation between bid and ask. The results of these impulse response functions for AMGN and INTC are shown in Fig. 2. We only show shocks for the bid 
Table 10

Covariance matrix of the nonlinear model for intel

\begin{tabular}{|c|c|c|c|c|c|c|c|c|c|}
\hline \multicolumn{10}{|c|}{ Panel A: Unrestricted covariance matrix } \\
\hline 0.082 & 0.041 & 0.043 & 0.035 & 0.040 & 0.039 & 0.039 & 0.037 & 0.032 & 0.039 \\
\hline 0.041 & 0.051 & 0.041 & 0.034 & 0.040 & 0.037 & 0.038 & 0.035 & 0.032 & 0.039 \\
\hline 0.043 & 0.041 & 0.101 & 0.038 & 0.042 & 0.039 & 0.040 & 0.036 & 0.033 & 0.040 \\
\hline 0.035 & 0.034 & 0.038 & 0.123 & 0.034 & 0.031 & 0.032 & 0.029 & 0.029 & 0.033 \\
\hline 0.040 & 0.040 & 0.042 & 0.034 & 0.076 & 0.038 & 0.039 & 0.036 & 0.034 & 0.065 \\
\hline 0.039 & 0.037 & 0.039 & 0.031 & 0.038 & 0.060 & 0.038 & 0.036 & 0.032 & 0.038 \\
\hline 0.039 & 0.038 & 0.040 & 0.032 & 0.039 & 0.038 & 0.050 & 0.036 & 0.033 & 0.038 \\
\hline 0.037 & 0.035 & 0.036 & 0.029 & 0.036 & 0.036 & 0.036 & 0.089 & 0.034 & 0.036 \\
\hline 0.032 & 0.032 & 0.033 & 0.029 & 0.034 & 0.032 & 0.033 & 0.034 & 0.129 & 0.034 \\
\hline 0.039 & 0.039 & 0.040 & 0.033 & 0.065 & 0.038 & 0.038 & 0.036 & 0.034 & 0.074 \\
\hline \multicolumn{10}{|c|}{ Panel B: Restricted covariance matrix } \\
\hline 0.082 & 0.036 & 0.036 & 0.036 & 0.036 & 0.039 & 0.036 & 0.036 & 0.036 & 0.036 \\
\hline 0.036 & 0.051 & 0.036 & 0.036 & 0.036 & 0.036 & 0.038 & 0.036 & 0.036 & 0.036 \\
\hline 0.036 & 0.036 & 0.101 & 0.036 & 0.036 & 0.036 & 0.036 & 0.036 & 0.036 & 0.036 \\
\hline 0.036 & 0.036 & 0.036 & 0.123 & 0.036 & 0.036 & 0.036 & 0.036 & 0.029 & 0.036 \\
\hline 0.036 & 0.036 & 0.036 & 0.036 & 0.076 & 0.036 & 0.036 & 0.036 & 0.036 & 0.065 \\
\hline 0.039 & 0.036 & 0.036 & 0.036 & 0.036 & 0.060 & 0.036 & 0.036 & 0.036 & 0.036 \\
\hline 0.036 & 0.038 & 0.036 & 0.036 & 0.036 & 0.036 & 0.050 & 0.036 & 0.036 & 0.036 \\
\hline 0.036 & 0.036 & 0.036 & 0.036 & 0.036 & 0.036 & 0.036 & 0.089 & 0.036 & 0.036 \\
\hline 0.036 & 0.036 & 0.036 & 0.029 & 0.036 & 0.036 & 0.036 & 0.036 & 0.129 & 0.036 \\
\hline 0.036 & 0.036 & 0.036 & 0.036 & 0.065 & 0.036 & 0.036 & 0.036 & 0.036 & 0.074 \\
\hline
\end{tabular}

This table reports the unrestricted and restricted covariance matrix for the stock Intel. The unrestricted covariance matrix is decomposed into a common factor (market-wide news) and idiosyncratic dealer components and takes the form

$$
\widetilde{\Omega}=\left[\begin{array}{ll}
\sigma_{\varepsilon}^{2} l l^{\prime}+\Xi^{b b} & \sigma_{\varepsilon}^{2} l l^{\prime}+\Xi^{b a} \\
\sigma_{\varepsilon}^{2} l l^{\prime}+\Xi^{a b} & \sigma_{\varepsilon}^{2} l l^{\prime}+\Xi^{a a}
\end{array}\right]
$$

where $\sigma_{\varepsilon}^{2}$ represents the market-wide component and $\Xi^{b b}, \Xi^{b a}, \Xi^{a b}$ and $\Xi^{a a}$ are the dealer idiosyncratic components.

quotes as the plots for the asks show similar patterns. These graphs show how the impact of a one standard deviation shock to a dealer affects the quotes of the other dealers.

For AMGN we see that the market makers have the largest impact on quotes. The second market maker, MLCO has the largest impact on the level of quotes, closely followed by the first market maker, MASH. Instinet has about the same impact on the quote level as the last market maker, SLKC. The Island ECN has the lowest impact.

For Intel we observe the opposite. For this stock ECNs affect quote levels most. In this case Island affects the quote level most, followed by Instinet. The market makers affect the quote level marginally, where we actually observe a slight decrease in the quote level.

A general result is that the impulse response functions relate to the ranking in spreads for dealers. For Amgen market makers have smaller spreads than the ECNs. In this case we observe that a shock to these dealers has a larger impact on the level of quotes than a shock to the ECNs. The opposite holds for Intel. These graphs indicate that price discovery and asymmetric information is related to the size of the spreads that dealers quote, which is in line with the theoretical framework of Kyle (1985).

The level of convergence is not the only relevant indicator of price discovery. Another relevant issue is the speed at which quotes converge to this level. This speed indicates how fast price discovery occurs and how quickly information of a particular dealer is incorporated into the quotes of other dealers. It also shows how transparent information of a particular dealer is to other dealers.

For Amgen we observe that the information in quote changes of the ECNs are incorporated fastest by the other dealers, with the fastest quote adjustment to Instinet. The slowest adjustment is to a quote change of market maker 2 (MLCO), which has the highest impact on the level of quotes. For Intel we observe the fastest quote adjustment to Island. Overall, information is incorporated more quickly for Intel, the more liquid stock, than for Amgen and 4. 

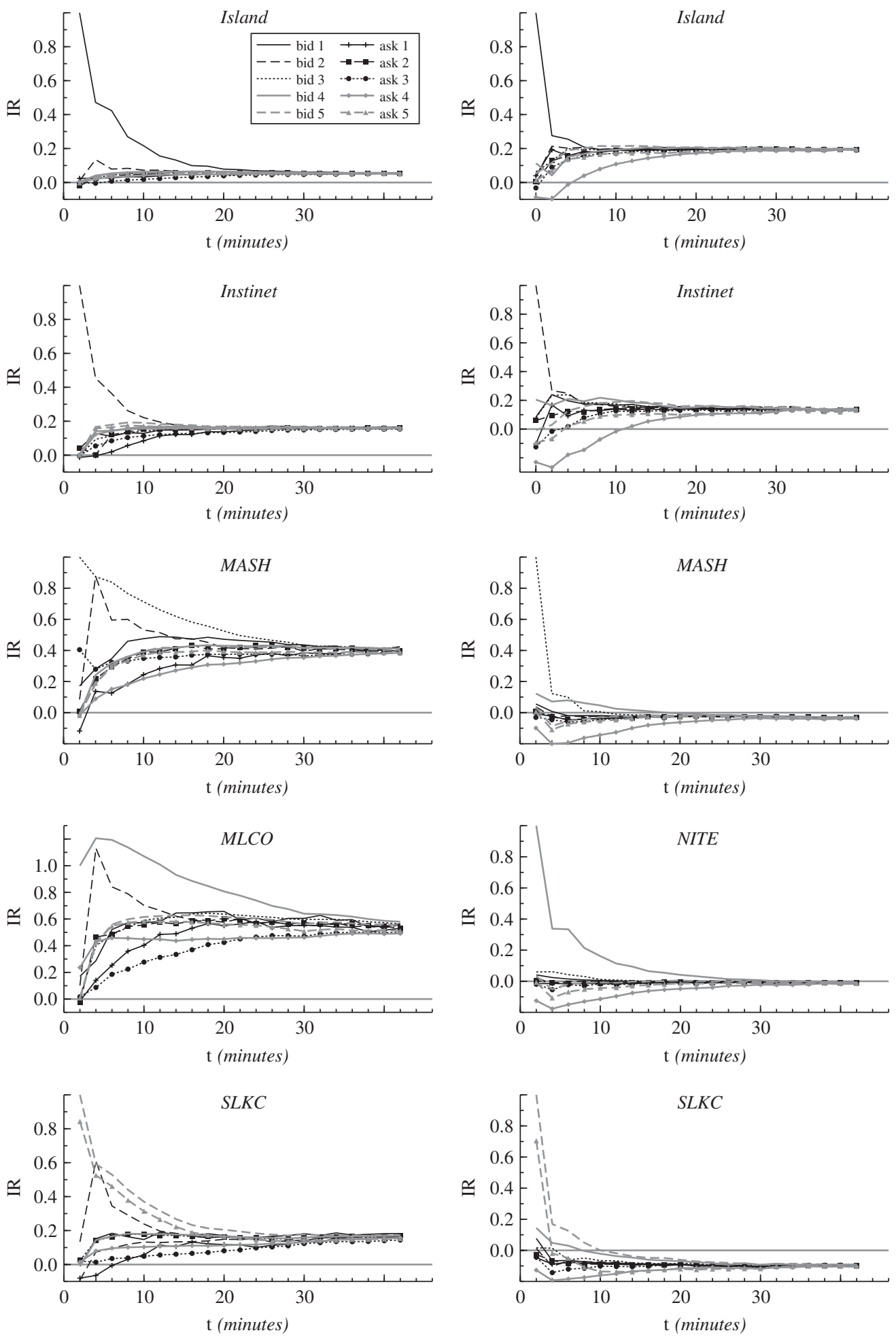

Fig. 2. Nonlinear impulse response functions for Amgen (left) and Intel (right), starting at average spreads, shock inwards. This figure shows nonlinear impulse response functions for the stocks Amgen and Intel. All dealers start at average spreads and each graph represents a one standard deviation inward shock (towards the inside quote) to a particular dealer quote (only bid quotes are displayed). The vertical axes in the graphs are measured in standard deviations the horizontal axes in time. The displayed graphs show the cumulative effect of a shock. 



Fig. 3. Nonlinear impulse response functions for Amgen (left) and Intel (right), starting at inside for dealer, shock inwards. This figure shows nonlinear impulse response functions for the stocks Amgen and Intel. All dealers start at the inside quote and each graph represents a one standard deviation inward shock to a particular dealer quote (only bid quotes are displayed). The vertical axes in the graphs are measured in standard deviations the horizontal axes in time. The displayed graphs show the cumulative effect of a shock. 

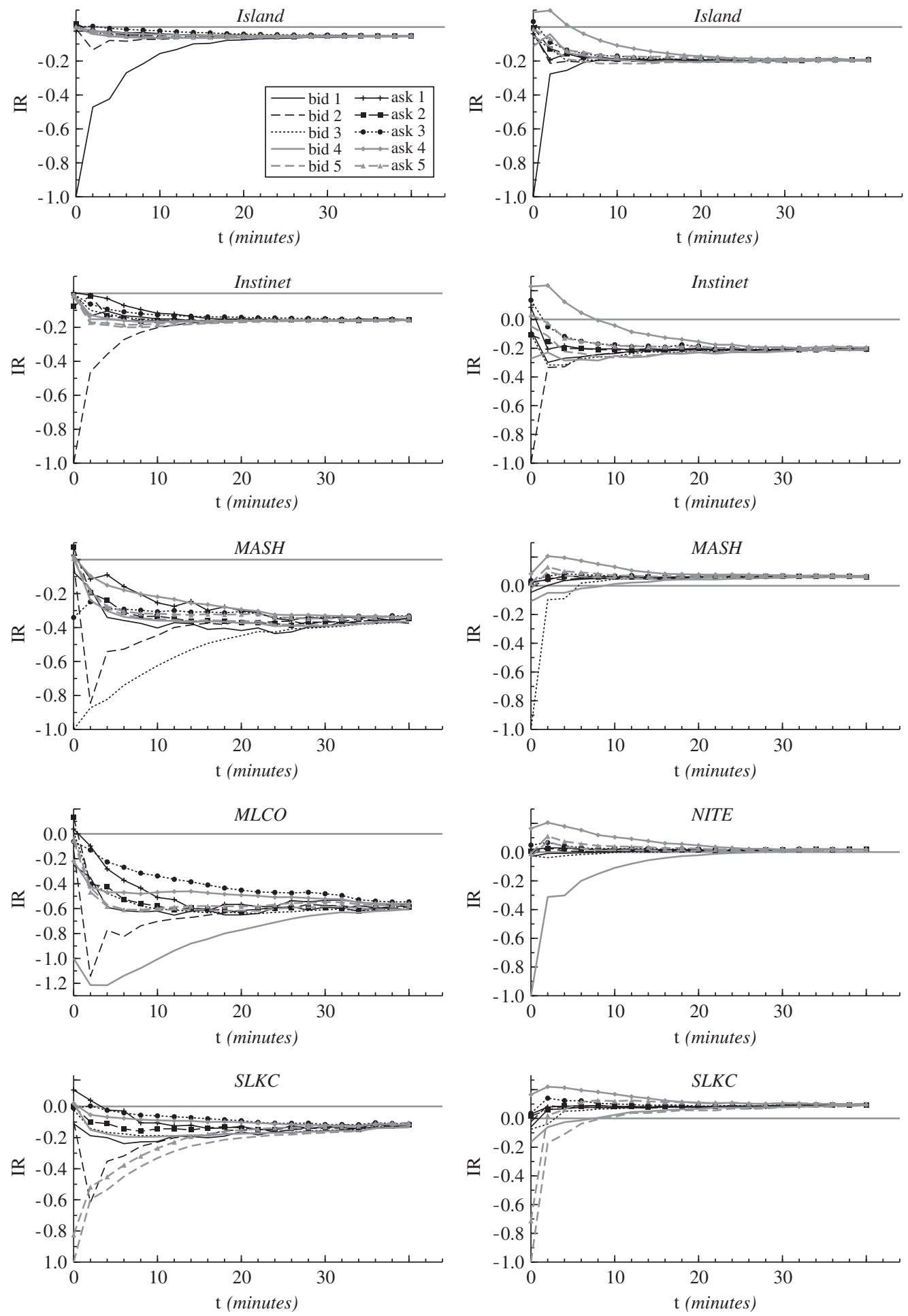

Fig. 4. Nonlinear impulse response functions for Amgen (left) and Intel (right), starting at inside for dealer, shock outwards. This figure shows nonlinear impulse response functions for the stocks Amgen and Intel. All dealers start at the inside and each graph represents a one standard deviation outward shock (away from the inside) to a particular dealer quote (only bid quotes are displayed). The vertical axes in the graphs are measured in standard deviations the horizontal axes in time. The displayed graphs show the cumulative effect of a shock. 

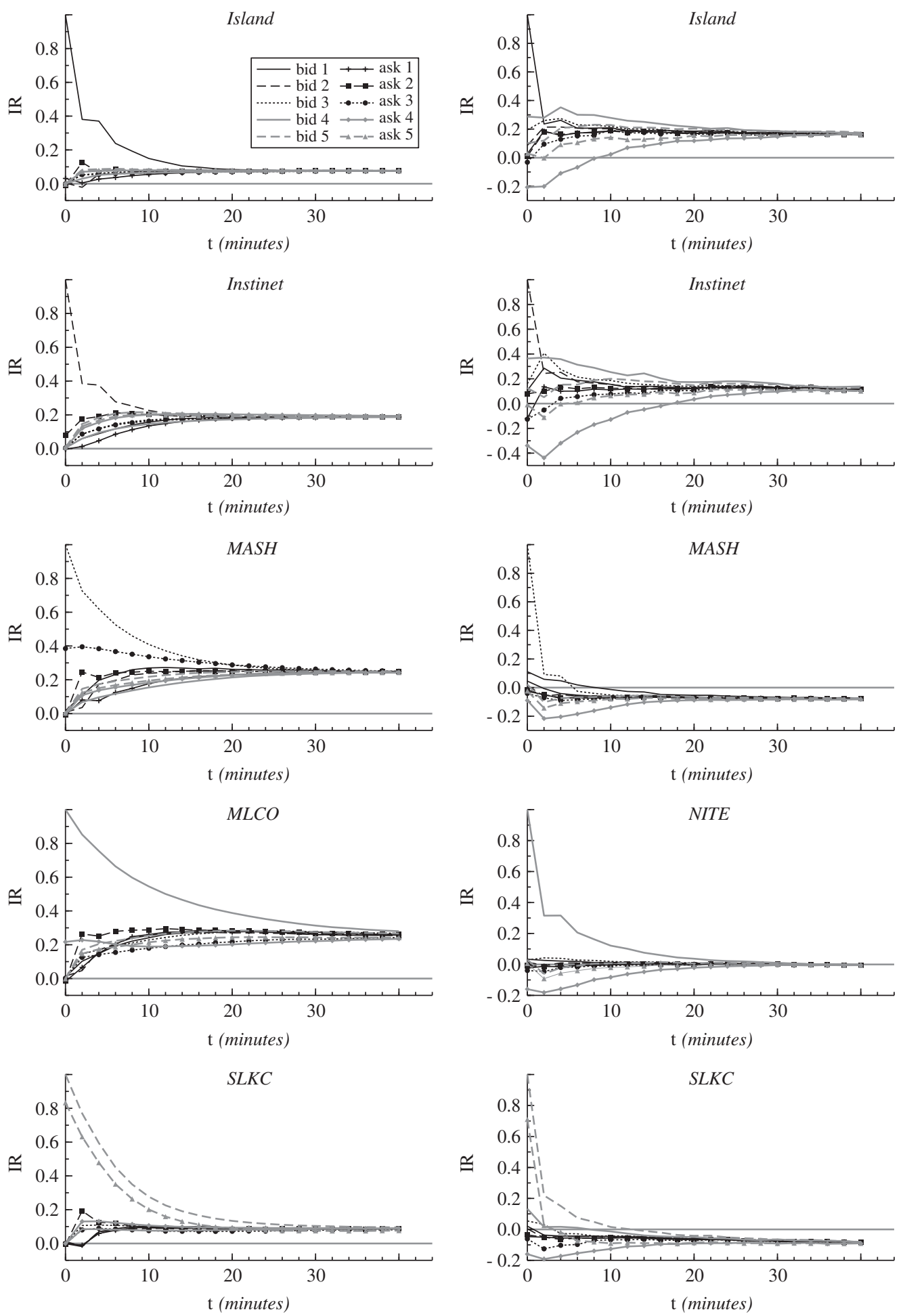

Fig. 5. Nonlinear impulse response functions for Amgen (left) and Intel (right), starting at average spreads, shock reaching inside. This figure shows nonlinear impulse response functions for the stocks Amgen and Intel. All dealers start at average spreads and each graph represents an inward shock reaching the inside to a particular dealer quote (only bid quotes are displayed). The vertical axes in the graphs are measured in standard deviations the horizontal axes in time. The displayed graphs show the cumulative effect of a shock. 

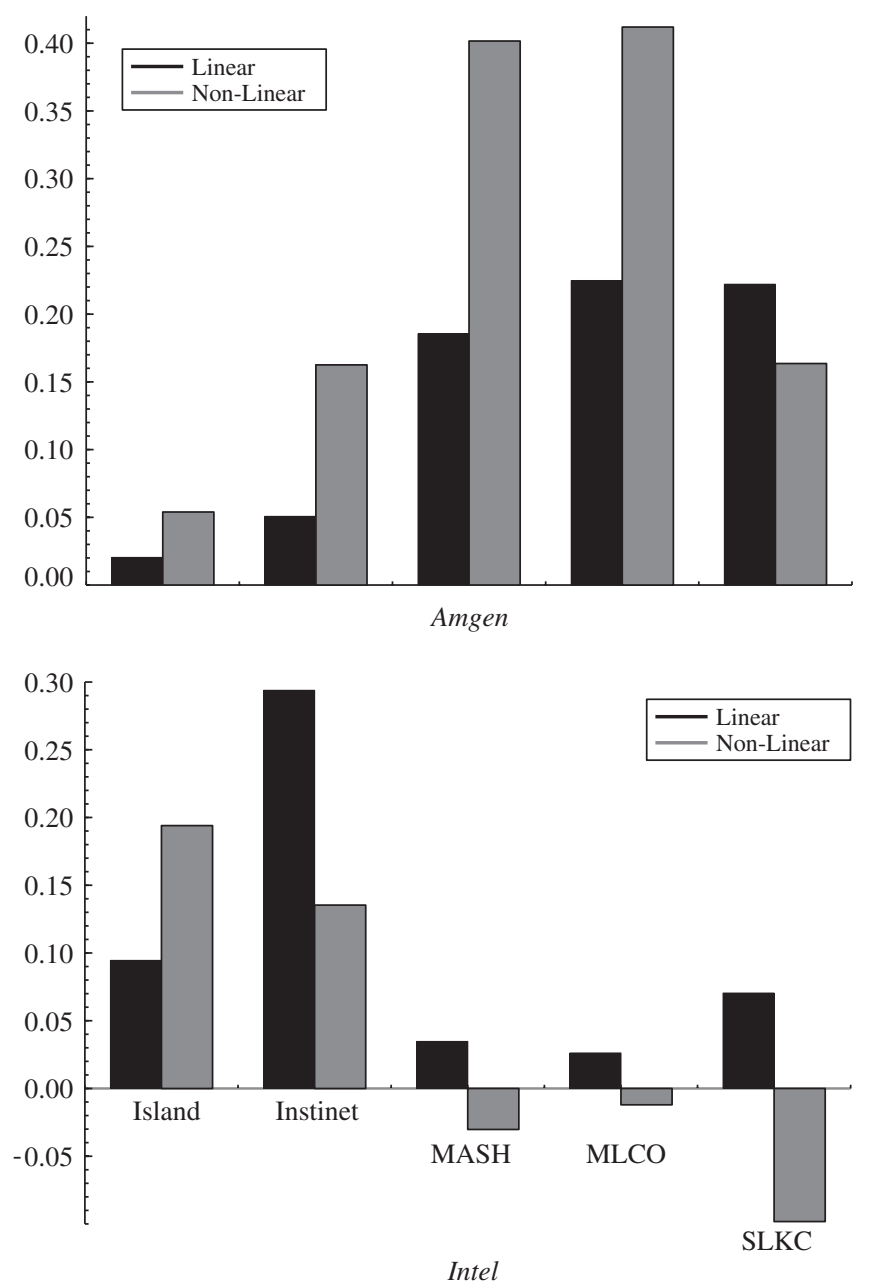

Fig. 6. Long-run impact of a one standard deviation shock for the linear and nonlinear impulse response function. This figure shows the long-run impact of a one standard deviation shock for both the linear and the nonlinear model. The unit of the vertical axes is in standard deviations and the horizontal axes show the particular dealers.

We consider the next two experiments jointly as they do not lead to any significant differences from the previous situation. The first experiment we consider is a one standard deviation shock inwards, where the particular dealer starts at the inside, all other dealers are at average spreads. The second experiment has the same initial situation as the first experiment but now we apply a shock outwards. Figs. 3 show the plots of these functions. There are some differences between the outcomes of the functions compared to the previous nonlinear impulse response function, but these are all marginal. Hence, we conclude that the initial situation does not influence the outcome of the function that much, and improving the inside or leaving the inside quote does not reveal any additional information.

The last experiment that we consider is a situation where all dealers start at average spread, where we apply a shock such that the respective dealer reaches the inside. The initial situation is equal to the situation of the first experiment, but the shock size differs. The plots of the impulse response functions are shown in Fig. 5. In this case we do observe some clear differences with the impulse responses in Fig. 2. Firstly, the impact that the market makers have on the quote level for Amgen is lower in this experiment. Moreover, the impact of Instinet increases even further and has a higher impact on the quote level than the last market maker. The last market maker has an impact approximately equal to the impact Island has. For Intel we only observe some marginal differences. 
Overall, the results of these responses show that the dynamics of quotes are insensitive to the initial situation, but more sensitive to the shock size.

The question remains whether these nonlinear impulse responses lead to different results than traditional linear impulse responses. As a robustness check we compute linear impulse responses. These are computed by estimating (1) imposing the restrictions in (3) and excluding the inside dummies. Although linear impulse responses are insensitive to the shock size and the history of the model, we do take the correlations between a dealer's bid and ask quote into account. These are determined by the decomposition in (7).

To compare the linear impulse responses to the nonlinear impulse responses we consider the long-run impact of a one standard deviation shock to a particular dealer for both functions. The nonlinear impulse response function considered is a one standard deviation shock inwards, starting at average spreads (see Fig. 2). The long-run impact is determined by the average level of bid and ask quotes of a particular dealer 40 minutes after the shock has been applied. In Fig. 6 we compare the linear impulse response function to the nonlinear impulse response function for both Amgen and Intel. Since standard errors of the long-run impact coefficients are never larger than 0.04 , the differences are statistically significant in most cases.

For Amgen we observe considerable differences between the linear and nonlinear specification. The largest difference is that in the nonlinear specification shocks have a larger impact on the level of quotes. The impulse responses also lead to a different view on the importance of dealers for the price discovery process. In the linear specification market makers 2 and 3 (MLCO and SLKC) appear to be the leading market makers. In the nonlinear specification the importance of SLKC declines, whereas the importance of the other MLCO and market maker 1 (MASH) increases.

For Intel we observe an opposite pattern. In general, the impact of a one standard deviation shock on the quote level declines in the nonlinear specification. Again the linear and nonlinear specification lead to different results in terms of price discovery. In the linear specification Instinet leads in terms of price discovery. For the nonlinear specification this is Island.

\section{Conclusion}

In this paper we propose a nonlinear error correction model for quote changes, which extends the linear model of Hasbrouck (1991). Nonlinear dynamics are introduced through the inside bid and ask quotes. The model allows quote adjustments to be different depending on who is currently at the inside and allows for an error correction towards the inside quotes instead of the midpoint. We test for a third form of nonlinearity in the distribution of the error terms, which we allow to depend on which dealer is at the inside.

Overall, we find that our model significantly improves the linear specification. Specifically, we find that all dealers strongly correct towards the inside quotes. However, all dealers, except Island, have the tendency to move away from the inside when they are at the inside. We further observe that all dealer move towards the inside quote when Island ECN is at the inside. Dealers react asymmetrically to the size of the spread, by raising their bid quote more than lowering their ask. The results for the regime-dependent heteroskedasticity tests remain inconclusive.

Finally, we discuss price discovery in an impulse response function framework. We use a conditional bootstrap to compute nonlinear impulse response functions. We find that the initial situation of the model does not affect the outcome of the function, but the size of the shock does. Further, the outcomes of the nonlinear model differ substantially from the outcomes of the linear model. Ignoring these nonlinearities leads to different conclusions towards who dominates in terms of price discovery.

\section{Acknowledgments}

We would like to thank Ronald Mahieu, Franz Palm, Christian Wolff and participants at the Market Microstructure Workshop in Madrid, March 2005, for their useful comments and suggestions.

\section{Appendix A}

Stock names and ticker symbols are reported in Table A.1. 
Table A.1

Ticker symbols and company names

\begin{tabular}{llll}
\hline Symbol & Company name & Symbol & Company name \\
\hline AAPL & Apple Computer Inc. & EGRP & E*TRADE Group, Inc. \\
AMAT & Applied Materials Inc. & INTC & Intel Corporation \\
AMGN & Amgen Inc. & MSFT & Microsoft Corporation \\
AMZN & Amazon.com Inc. & NOVL & Novell Inc. \\
ATHM & At Home Corporation & NXTL & Nextel Communications \\
CMGI & CMGI, Inc. & ORCL & Oracle Corporation \\
COMS & 3Com Corporation & PSFT & Peoplesoft Inc. \\
CPWR & Compuware Corporation & SUNW & Sun Microsystems Inc. \\
CSCO & Cisco Systems Inc. & WCOM & MCI WorldCom Inc. \\
DELL & Dell Computer Corporation & YHOO & Yahoo!, Inc. \\
\hline
\end{tabular}

\section{References}

Breusch, T., Pagan, A.R., 1979. A simple test for heteroskedasticity and random coefficient variation. Econometrica 47, 1287-1294.

Chan, K., Christie, W.G., Schultz, P.H., 1995. Market structure and the intraday pattern of bid-ask spreads for Nasdaq securities. J. Business 68 , $35-60$.

Christie, W.G., Schultz, P.H., 1994. Why do Nasdaq market makers avoid odd-eighth quotes? J. Finance 49, 1813-1840.

Christie, W.G., Harris, J.H., Schultz, P.H., 1994. Why did Nasdaq market makers stop avoiding odd-eighth quotes? J. Finance 49, $1841-1860$.

Chung, K.H., Zhao, X., 2003. Intraday variation in the bid-ask spread: evidence after the market reform. J. Finan. Res. 26, 191-206.

Engle, R.F., Patton, A.J., 2004. Impacts of trades in an error-correction model of quote prices. J. Finan. Markets 7, 1-25.

Eun, C., Sabherwal, S., 2003. Cross-border listings and price discovery: evidence from U.S. listed Canadian stocks. J. Finance 58, 549-576.

Harris, F., McInish, T.H., Chakravarty, R.R., 1995. Bids and asks in disequilibrium market microstructure: the case of IBM. J. Banking Finance 19, 323-345.

Hasbrouck, J., 1991. Measuring the information content of stock trades. J. Finance 46, 179-207.

Hasbrouck, J., 1995. One security, many markets: determining the contribution to price discovery. J. Finance 50, 1175-1199.

Hasbrouck, J., 1999. The dynamics of discrete bid and ask quotes. J. Finance 54, 2109-2142.

Huang, R.D., 2002. The quality of ECN and Nasdaq market maker quotes. J. Finance 57, 1285-1319.

Jang, H., Venkatesh, P., 1991. Consistency between predicted and actual bid-ask quote revisions. J. Finance 46, 433-446.

Koop, G., Pesaran, M.H., Potter, S.M., 1996. Impulse response analysis in nonlinear multivariate models. J. Econometrics 74, $119-147$.

Kyle, A.S., 1985. Continuous auctions and insider trading. Econometrica 53, 1315-1335.

Peiers, B., 1997. Informed traders, intervention, and price leadership: a deeper view of the microstructure of the foreign exchange market. J. Finance $52,1589-1613$.

Schultz, P.H., 2003. Who makes markets. J. Finan. Markets 6, 49-72.

Stoll, H.R., 1989. Inferring the components of the bid-ask spread: theory and empirical tests. J. Finance 44, 115-134.

Wang, J.-X., 2001. Quote revision and information flow among foreign exchange dealers. J. Int. Finan. Markets, Institutions and Money 11, 115-136. 